\title{
Inter- and Intraspecific Variation in the Artibeus species complex demonstrates size and shape partitioning among species
}

\author{
Brandon P Hedrick ${ }^{\text {Corresp. } 1}$ \\ ${ }^{1}$ Cell Biology and Anatomy, Louisiana State University Health Sciences Center- New Orleans, New Orleans, United States \\ Corresponding Author: Brandon P Hedrick \\ Email address: bphedrick1@gmail.com
}

Neotropical leaf-nosed bats (family Phyllostomidae) are one of the most diverse mammalian families and Artibeus spp. is one of the most speciose phyllostomid genera. In spite of their species diversity, previous work on Artibeus crania using linear morphometrics has uncovered limited interspecific variation. This dearth of shape variation suggests that differences in cranial morphology are not contributing to niche partitioning across species, many of which are often found in sympatry. Using two-dimensional geometric morphometric methods on crania from eleven species from the Artibeus species complex, the current study demonstrates substantial cranial interspecific variation, sexual size and shape dimorphism, and intraspecific geographic variation. The majority of species were shown to have a unique size and shape, which suggests that each species may be taking advantage of slightly different ecological resources. Further, both sexual size and shape dimorphism were significant in the Artibeus species complex. Male and female Artibeus are known to have sex specific foraging strategies, with males eating near their roosts and females feeding further from their roosts. The presence of cranial sexual dimorphism in the Artibeus species complex, combined with previous work showing that different fruit size and hardness is correlated with different cranial shapes in phyllostomids, indicates that the males and females may be utilizing different food resources, leading to divergent cranial morphotypes. Additional field studies will be required to confirm this emergent hypothesis. Finally, significant geographical shape variation was found in a large intraspecific sample of Artibeus lituratus crania. However, this variation was not correlated with latitude and instead may be linked to local environmental factors. Additional work on ecology and behavior in the Artibeus species complex underlying the morphological variation uncovered in this study will allow for a better understanding of how the group has reached its present diversity. 
1 Inter- and Intraspecific Variation in the Artibeus species complex demonstrates size and

2 shape partitioning among species

3

4 Brandon P. Hedrick ${ }^{1}$

$5{ }^{1}$ Department of Cell Biology and Anatomy, School of Medicine, Louisiana State University Health

6 Science Center, New Orleans, LA 70112, USA

7

8 Corresponding Author:

9

10 Brandon P. Hedrick

11

12

13

14 
15 Abstract:

16 Neotropical leaf-nosed bats (family Phyllostomidae) are one of the most diverse mammalian

17 families and Artibeus spp. is one of the most speciose phyllostomid genera. In spite of their

18 species diversity, previous work on Artibeus crania using linear morphometrics has uncovered

19 limited interspecific variation. This dearth of shape variation suggests that differences in cranial

20 morphology are not contributing to niche partitioning across species, many of which are often

21 found in sympatry. Using two-dimensional geometric morphometric methods on crania from

22 eleven species from the Artibeus species complex, the current study demonstrates substantial

23 cranial interspecific variation, sexual size and shape dimorphism, and intraspecific geographic

24 variation. The majority of species were shown to have a unique size and shape, which suggests that each species may be taking advantage of slightly different ecological resources. Further, both sexual size and shape dimorphism were significant in the Artibeus species complex. Male and female Artibeus are known to have sex specific foraging strategies, with males eating near their roosts and females feeding further from their roosts. The presence of cranial sexual dimorphism in the Artibeus species complex, combined with previous work showing that different fruit size and hardness is correlated with different cranial shapes in phyllostomids, indicates that the males and females may be utilizing different food resources, leading to divergent cranial morphotypes. Additional field studies will be required to confirm this emergent hypothesis. Finally, significant geographical shape variation was found in a large intraspecific sample of Artibeus lituratus crania. However, this variation was not correlated with latitude and instead may be linked to local environmental factors. Additional work on ecology and behavior in the Artibeus species complex underlying the morphological variation uncovered in this study will allow for a better understanding of how the group has reached its present diversity.

Los murciélagos neotropical de hoja nasal (filostómidos) son una de las familias mamíferas más diversas y Artibeus spp. es el género filostómido con más especies. A pesar de su riqueza de especies, trabajos anteriores sobre el cráneo Artibeus usando morfometría lineal han descubierto limitantes a la variación interespecífica. Esta falta de variación de forma sugiere la ausencia de partición de nicho en todas las especies, muchas de las cuales con frecuencia se encuentran en simpatría. Usando métodos geométricos morfométricos bidimensionales en una muestra grande de cráneos de once especies del complejo de especies Artibeus (Artibeus y Dermanura), el estudio actual demuestra una variación craneal interespecífica, dimorfismo sexual en tamaño y forma y variación geográfica intraespecífica. La mayoría de las especies mostraron un tamaño y forma únicos, lo cual sugiere que cada especie aprovecha nichos ligeramente distintos. Asimismo, el dimorfismo sexual en tamaño y forma fue significativo en el complejo de especies Artibeus. Los Artibeus machos y hembras tienen estrategias de forrajeo específicos al sexo, ya que los machos comen cerca de sus perchas y las hembras comen lejos de sus perchas. La presencia de dimorfismo sexual craneal en el complejo de especies Artibeus, al igual que trabajos anteriores que muestran que diferentes tamaños y durezas de fruta están relacionados con las diferentes formas craneales de filostómidos, indican que los machos y las hembras pueden estar utilizando recursos de alimento diferentes, llevando a morfotipos craneales divergentes. Por último, se encontró una considerable variación de tamaño geográfica en una muestra grande intraespecífica de cráneos de Artibeus lituratus. No obstante, esta variación no estuvo relacionada con la latitud y en cambio puede estar ligada a los factores ambientales locales. Trabajo adicional sobre la ecología y comportamiento del complejo de especies Artibeus subyacentes a la variación 
60

61

62

63

64

65

66

67

68

69

70

71

72

73

74

75

76

77

78

79

80

81

82

83

84

85

86

87

88

89

90

91

92

93

94

95

96

97

98

99

100

101

102

103

104

105

morfológica descubierta en este estudio hará posible un mejor entendimiento acerca de cómo el grupo ha logrado su diversidad actual.

Key Words: Phyllostomidae, Neotropical leaf-nosed bats, Chiroptera, geometric morphometrics

\section{Introduction}

Of the nearly 6500 species of extant mammals, more than $60 \%$ are rodents or bats (Burgin et al., 2018). Numerous factors such as novel functional innovation (the ever-growing teeth of rodents, wings of bats) and the repeated evolution of successful locomotor and foraging modes have led these mammal groups to diversify across the globe (Arita and Fenton, 1997; Kay and Hoekstra, 2009; Morales et al., 2019; Hedrick et al., 2020). One family of bats, the Neotropical leaf-nosed bats (Family Phyllostomidae) are often considered to represent an adaptive radiation and have diversified into more dietary niches than any other mammalian family (Freeman, 2000; Jones et al., 2005; Dumont et al., 2012; 2014; Shi \& Rabosky, 2015). Ancestrally insectivorous, phyllostomids have expanded into also eating fruit, nectar, blood, and leaves. Members of the Phyllostomidae are widespread throughout the Neotropics and are found in southern North America and throughout Central and South America. In spite of their dietary breadth and expansion across a wide geographical range, all phyllostomids are relatively small bats (7-200 g). How phyllostomids, and bats more generally, have been able to achieve their species diversity, especially when such a large number of species in the tropics live in sympatry, is an open question.

Artibeus is one of the most speciose genera in the Phyllostomidae (Lim et al., 2008) and has been considered to be a model for understanding bat diversification (Ferreira et al., 2014). The Artibeus species complex is composed of two groups, colloquially termed small Artibeus and large Artibeus, which are sometimes split at the genus level into Dermanura spp.

(corresponding to small Artibeus) and Artibeus spp. (corresponding to large Artibeus) (Redondo et al., 2008). All members of the Artibeus species complex eat fruit, subsisting primarily on figs, and the species complex spans geographically from Mexico to Argentina. The Artibeus species complex has also been shown to have relatively limited morphological variation (Balseiro et al., 2009; Marchán-Rivadeneira et al., 2010). However, size is an important discriminator among species (Ortega \& Castro-Arellano, 2001; Larsen et al., 2010) and may be one of the main factors allowing the Artibeus species complex to spread into separate niches. A better understanding of interspecific and intraspecific variation within the Artibeus species complex will grant further insight into not only the radiation of the Phyllostomidae, but also the diversification of mammalian species that live in sympatry.

Morphometrics is commonly used to quantify morphological shape for comparison with ecological variables to better understand how and why morphological variation within a group exists (Samuels \& Van Valkenburgh, 2008; Moore et al., 2015; Vander Linden et al., 2018; Hedrick et al., 2019). Caliper-based linear morphometrics have been previously used to assess interspecific variability in Artibeus (Lim, 1997; Guerrero et al., 2003; Lim et al., 2008; Balseiro et al., 2009; Larsen et al., 2010; Marchán-Rivadeneira et al., 2010), and these studies largely found that there was low interspecific variation across members of the genus. However, geometric morphometrics has been shown to be able to distinguish shape trends more effectively than linear morphometrics (Mutanen and Pretorius, 2007; Zelditch et al., 2012; Schmieder et al., 2015). Thus the relatively small differences in skull shape and size among Artibeus species will potentially be easier to capture and distinguish using geometric morphometrics in comparison 
106 with linear morphometrics as it captures shape more holistically and allows for better separation 107 of size and shape. This could potentially uncover previously unknown morphological size and

108 shape partitioning in the Artibeus species complex. However, geometric morphometric analyses have yet to be used to analyze variation in Artibeus.

The overarching goal of this study is to expand upon previous studies by employing geometric morphometrics on a sample of 279 crania for eleven species of the Artibeus species complex (22 species total) to address the following questions: (1) Do different members of the

113 Artibeus species complex differ in size and shape? Significant differences between species may suggest differences in niche partitioning via morphological innovation or conversely suggest non-adaptive processes such as genetic drift or non-morphological adaptive bases for niche partitioning (e.g., echolocation differences, biting behavior). (2) How have factors such as

117 phylogeny, sexual dimorphism, and geography structured that variation? Interspecific analyses

118 are done to evaluate differences in size, shape, and sexual dimorphism across the Artibeus

119 species complex. Based on previous studies (Marchán-Rivadeneira et al., 2010), I predict that the Artibeus species complex will separate into two clear size groups (small and large Artibeus) and that there will be additional separation within those two groups by size. Similarly, I predict that shape will not differ substantially across species following previous studies based on linear morphometrics (Balseiro et al., 2009; Marchán-Rivadeneira et al., 2010). I predict significant sexual dimorphism based on previous studies that have found male and female Artibeus species to exhibit differing foraging behaviors (Kunz \& Diaz, 1995). To assess intraspecific variation and geographical variation in the Artibeus species complex, A. lituratus is heavily sampled across its range. I hypothesize that there is shape and size variation across $A$. lituratus' range based on previous studies finding correlations between A. lituratus skull shape and environmental variables (Marchán-Rivadeneira et al., 2012). Using these data, I address the degree of morphological variation in the Artibeus species complex, discuss the underlying causes for that variation, and shed light on the radiation of the Artibeus complex.

\section{Materials \& Methods}

(a) Materials and Initial Analyses

Artibeus spp. $(\mathrm{n}=279)$ crania were photographed in lateral and ventral view at the Louisiana State University Museum of Natural Sciences (LSUMZ) using a Canon EOS 70D fitted with a Canon EF-S $60 \mathrm{~mm} \mathrm{f/2.8} \mathrm{Macro} \mathrm{USM} \mathrm{fixed} \mathrm{lens} \mathrm{mounted} \mathrm{on} \mathrm{a} \mathrm{photostand} \mathrm{to} \mathrm{ensure}$ the same angle was used in each picture. Two separate datasets were used, one to analyze interspecific variation $(\mathrm{n}=186)$ and one to analyze intraspecific variation in A. lituratus $(\mathrm{n}=$ 113). The interspecific sample included A. anderseni $(\mathrm{n}=8)$, A. phaeotis $(\mathrm{n}=20)$, A. cinereus $(\mathrm{n}$ =20), A. toltecus $(\mathrm{n}=14)$, A. aztecus $(\mathrm{n}=9)$, A. fraterculus $(\mathrm{n}=20), A$. obscurus $(\mathrm{n}=20), A$. jamaicensis $(\mathrm{n}=20)$, A. planirostris $(\mathrm{n}=20)$, A. lituratus $(\mathrm{n}=20)$, and $A$. fimbriatus $(\mathrm{n}=15)$ (Fig. 1). Classifications were done according to Rojas et al. (2016) who considered all of these species to belong to Artibeus, but note that A. anderseni, A. aztecus, A. cinereus, A. phaeotis, and A. toltecus are also sometimes classified as Dermanura. To reduce confusion, the term 'Artibeus species complex' is used in this study to refer to all species included in this study.

The intraspecific sample included populations of A. lituratus from Argentina $(\mathrm{n}=20)$, Belize $(n=6)$, Costa Rica $(n=11)$, Paraguay $(n=20)$, Peru $(n=20)$, Trinidad $(n=7)$, and two localities in Mexico (Colima, $n=8$; Tabasco, $n=21$ ). Each population here is named based on

150 the country of origin. 'Countries' were used as proxies for populations due to limited specimen 151 availability at individual localities in the visited museum collections. Generally, all specimens 
152 from each 'country' are quite close to one another geographically. Two populations were

153 sampled in Mexico, which are $\sim 1500 \mathrm{~km}$ apart and are thus referred by the Mexican state where

154 they were collected. Full details regarding collection information are present in the supplemental

155 information. A. lituratus was selected for analyzing intraspecific variation in Artibeus based on

156 its large range and its abundance and availability in the LSUMZ collections. I aimed to include

15720 specimens for each species and country respectively, but that was not always possible due to

158 limitations in the museum collections. All specimens were coded for sex and I aimed to have

159 equal numbers of males and females in each sample (53 males, 60 females; see Supplemental

160 Information). To keep sample sizes balanced in the interspecific analyses, the Argentina $A$.

161 lituratus specimens $(\mathrm{n}=20)$ were included in the interspecific dataset. A. lituratus specimens

162 from other localities were only examined in the intraspecific dataset.

163 Skulls were landmarked and semi-landmarked in tpsDIG2 (Rohlf, 2006) in lateral and

164 ventral views. Landmarks represent homologous anatomical loci while semi-landmarks represent

165 homologous curves. Eleven landmarks and one semi-landmark curve consisting of 15 semi-

166 landmarks were digitized in lateral view and seventeen landmarks and one semi-landmark curve

167 consisting of 10 semi-landmarks were digitized in ventral view (Fig. 2, Table S1). Landmarks

168 were imported into RStudio v. 1.1.463 (R Core Development Team, 2019) and opened in

169 geomorph v. 3.0.7 (Adams \& Otárola-Castillo, 2013). Landmarks were subjected to Generalized

170 Procrustes Analysis (GPA) and semi-landmarks were evenly spaced and were slid according to

171 the bending energy criterion (Bookstein, 1997; Perez et al., 2006; Zelditch et al., 2012). This

172 generated two centroid sizes per specimen (one lateral view and one ventral view). Each centroid

173 size was used in analyses with its corresponding shape data (e.g., lateral view centroid size

174 analyzed with lateral view shape data). An error analysis was performed whereby one individual

175 (LSUMZ 9425) was landmarked 10 additional times in both lateral and ventral views to assess

176 within individual landmarking error. All replicates of this specimen were then plotted in

177 principal component morphospace to evaluate general shape trends and ensure that the replicates

178 of the same individual clustered together closely with other replicates (Fig. S1), prior to running

179 analyses on the dataset as a whole.

180

181

182

183

184

185

186

187

188

189

190

191

192

193

194

195

196

197

\section{(b) Interspecific Data Analyses}

To analyze trends in the data, both lateral and ventral landmark configurations were subjected to principal component analysis (PCA). Principal components (PCs) that represented greater than $10 \%$ of total shape variation were examined. To address whether shape varied by size for both the lateral and ventral datasets, relationships between the common allometric component (CAC) of shape variation (Mitteroecker et al., 2004) were tested against log10transformed centroid size using a Procrustes ANOVA that was permuted 999 times. The CAC represents the allometric trend in the data. These data were represented graphically both as regressions and using violin plots of log10-transformed centroid size. Additionally, Procrustes ANOVAs were done to analyze the relationship between shape, species, sex, and size (shape species $*$ sex $*$ size) in both views where size was represented by $\log 10$-transformed centroid size. Finally, sexual size dimorphism was analyzed in both views (size $\sim$ species $*$ sex). Due to sample size limitations, sexual dimorphism was examined in the Artibeus species complex as a whole, and in A. lituratus, which was sampled at a higher rate for the intraspecific analyses (see below).

Species means of shape for lateral and ventral views were then taken for all 11 species to quantify the degree of phylogenetic signal in the data. Species means were first subjected to GPA.

Peer) reviewing PDF | (2020:09:52705:2:0:NEW 21 Jun 2021) 
198 Shape data and $\log 10$-transformed centroid sizes were evaluated for phylogenetic signal using

199 Blomberg's K statistic modified for multivariate shape data (Kmult) (Blomberg et al., 2003;

200 Adams, 2014) in geomorph. This was done using the phylogeny from Rojas et al. (2016). In

201 addition to the Procrustes ANOVAs discussed above, phylogenetically-corrected Procrustes

202 ANOVAs were performed on means data. This required combining each species into a single

203

204

205

206

207

208

209

210

211

212

213

214

215

216

217

218

219

220

221

222

223

224

225

226

227

228

229

230

231

232

233

234

235

236

237

238

239

240

241

242

243 mean (thereby losing the sex component). The species phylogeny was plotted onto a PCA of mean shapes to visually examine how phylogeny and morphology related to one another in morphospace. To better understand the evolutionary processes that underlie phylogenetic signal in the data, patterns of disparity accumulation through time were calculated using the dtt function in geiger (Harmon et al., 2008). By analyzing disparity through time, it is possible to better understand whether shape evolved under a Brownian motion pattern or through punctuated bursts of disparity.

In order to further analyze differences between species, the nicheROVER package (Swanson et al., 2015) was utilized. This analysis was developed to evaluate niche overlap with multidimensional data and has been previously applied to shape data (Machado et al., 2018). Separate analyses were run for the lateral and ventral datasets utilizing principal components 1 and 2 and $\log 10$-transformed centroid size to quantitatively assess how much overlap is present in shape and size between species pairs. Posterior distributions were generated for these values for each species using 10,000 permutations. The overlap function was then used to calculate overlap metric estimates at a $95 \%$ confidence interval. Finally, the posterior probabilities that a given species overlaps with another species in size and shape were plotted.

\section{(c) Intraspecific Data Analyses}

Lateral and ventral A. lituratus crania were subjected to PCA as was done in the interspecific analyses. Procrustes ANOVAs were performed to assess the relationship between shape, sex, size, and country (shape $\sim$ sex + size + country) in both views, with size represented by $\log 10$-transformed centroid size. Posthoc tests were performed using the advanced.procD. $1 \mathrm{~m}$ function in geomorph to generate pairwise comparisons (Collyer et al., 2015). Sexual size dimorphism was assessed in base R (size $\sim$ country + sex) for both views.

To visualize how close individuals in portions of the geographic range (countries) cluster to one another, distance matrices based on Euclidean distances were calculated for country means in base R using all principal components for both lateral and ventral datasets (R Core Development Team, 2019). Hierarchical clustering was then performed using unweighted pairgroup method with arithmetic means (UPGMA) through the hclust function. These clusters were then plotted as dendrograms. To determine how well the dendrograms reflect the underlying hierarchical structure, the cophenetic correlation coefficient was calculated (Sneath \& Sokal, 1973). This compares heights of tips above the node that they are joined to with the observed correlation matrix (Zelditch et al., 2012).

\section{Results}

(a) Interspecific Results:

In principal component space, large Artibeus and small Artibeus groups separated in the lateral and ventral datasets along PC1 (Fig. 3, Fig. S2 for colorblind version). The separation is less clear in the lateral dataset than the ventral dataset (see Table $\mathrm{S} 2$ for full results).

In the lateral PCA, PC1 accounted for $54.5 \%$ of total variation. The small Artibeus (A. anderseni, A. phaeotis, A. cinereus, A. toltecus, and A. aztecus) plotted on the negative PC1 axis 
244 while the large Artibeus (A. fraterculus, A. obscurus, A. jamaicensis, A. planirostris, A. lituratus,

245

246

247

248

249

250

251

252

253

254

255

256

257

258

259

260

261

262

263

264

265

266

267

268

269

270

271

272

273

274

275

276

277

278

279

280

281

282

283

284

285

286

287

288

289 and $A$. fimbriatus) plotted on the positive PC1 axis. While PC1 was largely structured by size, some of the largest (e.g., A. lituratus) and smallest (e.g., A. cinereus) species plotted towards the center of morphospace rather than on the ends defined by PC1. Therefore, PC1 incorporated both size and shape data. Taxa on the negative end of $\mathrm{PC} 1$ tended to have a shorter rostrum than those on the positive end of PC1 (Fig. 3A). PC2 accounted for $17.5 \%$ of total variation and separated out species within larger clusters. Specimens on the positive end of PC2 had a less pronounced dome shape to their crania than those on the negative end of PC2. Specimens on the negative end of PC2 also had a more caudally positioned zygomatic arch relative to the position of the external acoustic meatus. Within the small Artibeus cluster, A. phaeotis, A. toltecus, and A. anderseni plotted on the negative PC2 axis while $A$. aztecus and $A$. cinereus plotted on the positive PC2 axis. A. cinereus overlapped strongly with A. jamaicensis and A. fraterculus. In the large Artibeus cluster, all taxa plotted in one large poorly differentiated group. However, $A$. fimbriatus and A. planirostris tended to have higher PC1 scores than the other large Artibeus species. Additional PCs accounted for less than $10 \%$ of total variance.

Shape and log-transformed centroid size were significantly correlated for the lateral dataset $\left(\mathrm{p}<0.001, \mathrm{R}^{2}=0.369\right)$. The small Artibeus group and large Artibeus group separated in centroid size and shape (Fig. 4A). All small Artibeus species occupy different sizes with minimal overlap (Fig. 4B). A. cinereus and A. toltecus overlap along the common allometric component of shape, but have different size ranges $(A$. cinereus mean $\mathrm{CS}=3.57$, A. toltecus mean $\mathrm{CS}=$ 3.81). A. aztecus and A. phaeotis show a similar situation where they overlap in shape, but not in size (Fig. 4A, B). A. anderseni is the smallest taxon included (mean CS $=3.28$ ). There are two size groups for the large Artibeus taxa, one including A. fraterculus, A. obscurus, and $A$. jamaicensis and the other including A. lituratus, A. planirostris, and A. fimbriatus (Fig. 4B). Within the smaller large Artibeus cluster, A. fraterculus and A. jamaicensis overlap in shape, but A. obscurus does not. In the larger large Artibeus cluster, A. planirostris and A. fimbriatus overlap in shape, but $A$. lituratus does not.

Similar to the lateral PCA, in the ventral dataset large and small Artibeus are separated with small Artibeus plotting on the negative end of $\mathrm{PC} 1$ and large Artibeus plotting on the positive end of PC1 (Fig. 3B). Unlike the lateral PCA, the two clusters do not have any overlap. $\mathrm{PC} 1$ accounted for $51.7 \%$ of the total variance and $\mathrm{PC} 2$ accounted for $11.4 \%$ of total variance. Additional PCs accounted for less than $10 \%$ of the total variance. Taxa on the negative end of PC1 had a relatively shorter rostrum and longer basicranium than those on the positive end of PC1. Along PC1, the large Artibeus cluster had a clear separation between an overlapping group composed of A. lituratus, A. jamaicensis, A. fraterculus, and A. obscurus and a group composed of A. fimbriatus and A. planirostris. A. fimbriatus and A. planirostris were further separated along PC2. Within the small Artibeus group, PC2 separated A. cinereus from the other small Artibeus taxa (A. phaeotis, A. aztecus, A. toltecus, and A. anderseni), which overlapped. Specimens on the negative end of PC2 had a wider skull with a more curved zygomatic arch than those on the positive end of PC2.

Size and shape were similarly correlated in the ventral dataset $\left(\mathrm{p}<0.001 ; \mathrm{R}^{2}=0.461\right)$. Compared to the lateral dataset, the taxa had less spread along the common allometric coefficient shape axis (Fig. 4C). The log-transformed centroid size spread for the lateral dataset and the ventral dataset strongly agreed (Figs. 4B, D). As in the lateral dataset, the small and large Artibeus groups were strongly separated in centroid size. A. anderseni differed in size and shape from other small Artibeus taxa. However, A. phaeotis, A. cinereus, A. toltecus, and A. aztecus all

Peer) reviewing PDF | (2020:09:52705:2:0:NEW 21 Jun 2021) 
290

291

292

293

294

295

296

297

298

299

300

301

302

303

304

305

306

307

308

309

310

311

312

313

314

315

316

317

318

319

320

321

322

323

324

325

326

327

328

329

330

331

332

333

334

335

overlapped on the shape axis. The large Artibeus taxa split into two size-based groups as in the lateral dataset. Unlike the lateral dataset, A. fraterculus, A. obscurus, and A. jamaicensis overlapped on the shape axis. Similar to the lateral dataset, A. planirostris, A. lituratus, and A. fimbriatus form a cluster. A. planirostris and $A$. fimbriatus have similar sizes and shapes whereas A. lituratus has a different shape from the other two taxa.

NicheROVER analyses similarly demonstrated minimal overlap between species when size and shape $(\mathrm{PC} 1,2)$ axes were considered (Fig. S3, S4). In lateral view, only A. jamaicensis and $A$. fraterculus and $A$. lituratus, $A$. fimbriatus, and $A$. planirostris had more than $50 \%$ mean overlap. In ventral view, $A$. jamaicensis, $A$. fimbriatus, and $A$. obscurus had over $50 \%$ mean overlap, but other species did not.

Based on the Procrustes ANOVA of the lateral shape dataset (Tables 1, S3), all main factors (species, sex, and size) were significant $(\mathrm{p}<0.001)$. Further, the interaction of species and sex was also significant $(\mathrm{p}<0.001)$ showing that different sexes are different shapes for different species (intraspecific sexual shape dimorphism). The interaction of species and size was also significant $(\mathrm{p}<0.001)$. Shape and the interaction of sex and size was not significant $(\mathrm{p}=$ 0.919). Finally, the interaction of species, sex, and size was significant with respect to shape ( $\mathrm{p}<$ $0.001)$ showing that allometric relations change with species and with each sex in each species. The trends for the ventral dataset (Table 2) were the same except that the interaction of sex and size was significant $(\mathrm{p}=0.003)$.

In lateral view, both shape $\left(\mathrm{K}_{\text {mult }}=0.80, \mathrm{p}=0.008\right)$ and size $\left(\mathrm{K}_{\text {mult }}=2.51, \mathrm{p}<0.001\right)$ were significantly correlated with phylogeny. Similarly, the ventral dataset showed that both shape $\left(\mathrm{K}_{\text {mult }}=1.04, \mathrm{p}=0.007\right)$ and size $\left(\mathrm{K}_{\text {mult }}=2.50, \mathrm{p}<0.001\right)$ were significantly correlated with phylogeny (see Table S4 for PCA results). Mapping the phylogeny on the species means in principal component space demonstrates a separation between small and large Artibeus in morphospace with less clear trends within each group (Fig. S5A, S5B). In lateral view, there is a peak in disparity at approximately 5 mya, which is at the timing of the split between small and large Artibeus (Fig. S5C). This suggests a burst in morphological disparity at that time. Disparity accumulation in ventral view generally follows Brownian motion with a small increase in disparity at 5 mya (Fig. S5D). Using phylogenetically corrected Procrustes ANOVAs, neither size nor species were significantly correlated with lateral or ventral shape (Table S4). This is likely due to the strong separation in both size and shape between the small Artibeus and large Artibeus, which each form a monophyletic group. Given a large amount of individual variation and species overlap, the mean shapes are likely simplifying the trends and reducing the signal. Therefore, the discussion will largely concern the non-phylogenetically corrected results recognizing that there is a phylogenetic component to cranial shape in the Artibeus species complex.

\section{(b) Intraspecific Results:}

Although there was a substantial amount of overlap in principal component space, $A$. lituratus specimens grouped by locality (country) in both the lateral and ventral datasets, demonstrating some intraspecific geographic variation within A. lituratus (Fig. 5; see Table S5 for full results).

In the lateral dataset, $\mathrm{PC} 1$ accounted for $31.7 \%$ of the total variation and PC2 accounted for $24.1 \%$ of the total variation (Fig. 6A). Specimens on the positive PC1 axis had relatively longer zygomatic arches and a somewhat more compact skull. Specimens from Argentina exemplified this morphotype. Specimens on the negative end of PC1 had shorter zygomatic 
336 arches with a less compact skull, shown by specimens from Trinidad. While these specimens

337

338

339

340

341

342

343

344

345

346

347

348

349

350

351

352

353

354

355

356

357

358

359

360

361

362

363

364

365

366

367

368

369

370

371

372

373

374

375

376

377

378

379

380

381

group by country in morphospace, it should be noted that the shape differences are quite minor. In the ventral dataset, $\mathrm{PC} 1$ accounted for $25.9 \%$ of total variation while PC2 accounted for $13.4 \%$ of total variation (Fig. 6C). Specimens on the positive PC1 axis had somewhat more compact skulls with flatter zygomatic aches, exemplified by specimens from Argentina and Paraguay, than taxa at the negative end of PC1. However, as with the lateral dataset, these shape differences were quite minor in spite of clear country-based groupings in morphospace.

Based on a Procrustes ANOVA (lateral shape $\sim$ sex + size + country), lateral shape was significantly correlated with sex $(p=0.002)$, size $(p<0.001)$, and country $(p<0.001)$. Additional pairwise tests were performed to establish significances between countries using the advanced.procD.lm function in geomorph (See Table 3, above diagonal for lateral view; for Zscores, see Table S6). Cranial centroid size in lateral view was lower in the northern localities (Belize, Mexico, Costa Rica) in comparison with the southern ones (Peru, Trinidad, Paraguay, Argentina) (Table 4). The ventral shape dataset was significantly corelated with size $(\mathrm{p}<0.001)$ and country $(\mathrm{p}<0.001)$, but not sex $(\mathrm{p}=0.39)$ under the Procrustes ANOVA model (ventral shape $\sim$ sex + size + country). Pairwise comparisons showed fewer significant differences in the ventral dataset in comparison with the lateral dataset (Table 3, below diagonal for ventral view; for Z-scores, see Table S6). Size was significantly correlated with country in both lateral ( $\mathrm{p}<$ $0.001)$ and ventral $(p<0.001)$ views. Sex was correlated with size in lateral view $(p=0.027)$, but was marginally significant in ventral view $(\mathrm{p}=0.063)$. The average centroid size in ventral view strongly correlated with the average centroid size in lateral view such that the more northern countries had smaller average centroid sizes than the more southern countries (Table 4).

The UPGMA analyses had cophenetic coefficients that suggest that the dendrograms do display underlying hierarchy (lateral dataset cophenetic coefficient $=0.85$; ventral dataset cophenetic coefficient $=0.83$ ). In both datasets, the Mexican localities, Costa Rica, and Trinidad formed a cluster (Figs. 6B; 6D). This did not include Belize in either case. In the lateral dataset, Belize and Peru grouped together and Argentina and Paraguay grouped together. In ventral view, Belize and Paraguay grouped together and Argentina and Peru grouped together.

\section{Discussion}

Speciation can occur through numerous avenues, including vicariance or via modifications in resource use of species in sympatry. Quantifying morphological variation can grant insight into how species may be converging on similar morphologies or diverging into disparate morphologies, whether that is occurring interspecifically or intraspecifically across a wide geographical range. As a result, such analyses help to shed light onto the underlying mechanisms structuring the degree of morphological variation in a group. Bats are one of the most diverse mammalian groups, with numerous species living in sympatry with closely related species. The phyllostomids are one of the most diverse bat families (Shi \& Rabosky, 2015) and the Artibeus species complex is highly diverse within the Phyllostomidae, making them an excellent group with which to ask questions about interspecific and intraspecific morphological variation. The present study demonstrates that species within the Artibeus species complex have diverged into discordant morphologies and/or sizes, potentially allowing them to occupy different niches. Further, significant intraspecific differences were found within A. lituratus across its range, demonstrating that within species variation is an important factor to consider when analyzing skull shape in bats. However, no clear patterns of geographical variation were found.

Peer] reviewing PDF | (2020:09:52705:2:0:NEW 21 Jun 2021) 
382

383

384

385

386

387

388

389

390

391

392

393

394

395

396

397

398

399

400

401

402

403

404

405

406

407

408

409

410

411

412

413

414

415

416

417

418

419

420

421

422

423

424

425

426
Interspecific Variation of the Artibeus Species Complex

This study demonstrated clear species level differences in cranial size and shape across the Artibeus species complex (Tables 1;2), which may suggest niche partitioning of species if these differences impact biting performance or resource use. The present study confirmed the broad size difference between small and large Artibeus found in prior studies that used linear morphometrics (Lim, 1997; Ortega \& Castro-Arellano, 2001; Larsen et al., 2010; MarchánRivadeneira et al., 2010). Principal component 1 in lateral and ventral views were largely related to size and showed clear separation between these two groups (Fig. 3). This result was corroborated by an allometric analysis demonstrating a significant relationship between size and shape with small Artibeus species separating fully from large Artibeus species in both lateral (Fig. 4A) and ventral (Fig. 4C) views. It was further shown by a lack of overlap in size and shape variables (Fig. S3, S4).

In addition to the division between the broader small and large Artibeus groups, the present analysis found fine-scale size and shape-based divisions within each group. While some previous studies have found species level differences in cranial shape variation in the Artibeus species complex (Lim et al., 2008), the majority of previous studies have found that cranial shape does not substantially vary within either large or small Artibeus groups (e.g., Balseiro et al., 2009; Marchán-Rivadeneira et al., 2010). Two clear size-based groups were found in the large Artibeus, which are present in both lateral view (Fig. 4B) and ventral view (Fig. 4D). The first group included $A$. fraterculus, $A$. obscurus, and $A$. jamaicensis and the second included $A$. planirostris, A. lituratus, and $A$. fimbriatus. This is in agreement with Ortega and CastroArellano (2001), who noted that $A$. planirostris and $A$. fraterculus differed in size. Variation in shape across these species was also present, with $A$. obscurus having a different shape from $A$. fraterculus and $A$. jamaicensis in the first group and $A$. lituratus having a different shape than $A$. planirostris and A. fimbriatus in the second group (Fig. 4A, C). Additionally, the small Artibeus had clear size separation across all species examined (A. anderseni, A. phaeotis, A. cinereus, $A$. toltecus, and A. aztecus). Just like with the large Artibeus, the small Artibeus differed in shape as well, with $A$. cinereus and $A$. toltecus having similar shapes, which were different from $A$. phaeotis and A. aztecus, especially in lateral view (Fig. 4A). A. anderseni had a different shape from all small Artibeus species. Overall, the majority of species differed from one another in cranial size, shape, or a combination of the two (Fig. S3; S4).

Phylogeny was significantly correlated with skull shape in both the lateral and ventral datasets. Phylogenetic comparative methods using species means showed a lack of significance between shape, size, and species (Table S4), which may suggest that some of the shape differences across species uncovered in the non-phylogenetically corrected ANOVAs may be related to allometric differences or drift rather than morphological changes related to skull function. This lack of significance may also be related to the strong divide in both shape and size between large and small Artibeus. Examining shape data of species means in a phylomorphospace revealed strong clustering of small Artibeus and large Artibeus species, but less phylogenetic influence within each broader group (Fig. S5A, B). Evaluating disparity through time demonstrated a spike in disparity at the time when the small and large Artibeus split (Fig. S5C, D). This supports the idea that the main phylogenetic influence in the data was the division between small and large Artibeus, which are sometimes considered separate genera (Redondo et al., 2008). 
427

428

429

430

431

432

433

434

435

436

437

438

439

440

441

442

443

444

445

446

447

448

449

450

451

452

453

454

455

456

457

458

459

460

461

462

463

464

465

466

467

468

469

470

471

472

Behavioral plasticity in feeding habits can drive variation both within species and between species. Dumont and O'Neal (2004) found that different pteropodid species perform different biting behaviors when eating fruits of different hardnesses and suggested that some species access hard fruit diets by changing behavior while others may do so through morphological changes. Recently, Hedrick et al. (2020) showed that it is likely behavioral plasticity rather than morphological shape change of their proximal limb bones that has allowed diversification of rodents into varied locomotor niches, suggesting that behavioral plasticity rather than morphological change can facilitate diversification. Therefore, it is likely that morphological variation is not the only factor that has allowed the Artibeus species complex to proliferate, and that behavioral plasticity may be another factor. Although figs make up 78\% of the diet of Artibeus jamaicensis (Ortega \& Castro-Arellano, 2001) and Artibeus spp. has been considered a specialist on Cecropiaceae and Moraceae (Fleming, 1986), fig trees are not available as a food resource at all times of the year (August, 1981). For example, A. jamaicensis and A. lituratus have been shown to be folivorous for part of the year (Zortéa \& Mendes, 1993; Kunz \& Diaz, 1995) and A. lituratus is known to have a more generalist diet in regions where figs are not as abundant (Galetti \& Morellato, 1994). Given annual dietary variation, a combination of morphological and behavioral plasticity may have led Artibeus spp. to have a previously unrecognized amount of both interspecific and intraspecific variation. Small Artibeus species tend to have a taller, more dome shaped skull with a shorter rostrum, indicating a higher mechanical advantage than the less tall, rostrocaudally long skulls of large Artibeus species (Fig. 3). Since the small Artibeus species have smaller skulls compared to the large Artibeus, they may compensate for their small skull size by enhancing their mechanical advantage to consume hard figs that the large Artibeus species are able to eat as a result of their larger skull size.

Alternatively, morphological variation in Artibeus spp. may be related to allometry or drift rather than function. Future work evaluating skull shape variation in Artibeus spp. across its geographical range in connection with field studies demonstrating which fruits are eaten at each locality will help to establish a form-function relationship. Such work will also uncover the role of behavioral and dietary plasticity in Artibeus spp. to allow a better understanding of how these factors and the morphological diversity demonstrated in the present study may have shaped the evolution of the Artibeus species complex.

\section{Sexual Dimorphism}

In addition to interspecific morphological variation, this study showed that both sexual size dimorphism and sexual shape dimorphism were present in lateral and ventral views in the Artibeus species complex as a whole. A. lituratus had significant sexual shape and size dimorphism in lateral view, but not in ventral view. In lateral view, the females had a lower skull profile than males (Fig. 7A). Further, A. lituratus females were larger than males (Fig. 7C, D). Female $A$. obscurus have also been noted to be larger than males (Brosset \& Charles-Dominique, 1990; Eisenberg \& Redford, 1989; Simmons \& Voss, 1998). As sexual size dimorphism is present in lateral view for A. lituratus and is only marginally significant in ventral view (Table S6), even though the two size metrics strongly agree, the two-dimensional view used to calculate centroid size may have a bearing on significance. Further, since sexual dimorphism was assessed in the interspecific data at the genus level as a result of sample size limitations, it is not possible to determine which specific Artibeus species were sexually dimorphic (with the exception of $A$. lituratus). Given the low $\mathrm{R}^{2}$ value associated with sex in the interspecific data, it is likely that some species display sexual dimorphism while others do not. A deeper analysis of other Artibeus

Peer) reviewing PDF | (2020:09:52705:2:0:NEW 21 Jun 2021) 
473 species with large sample sizes, similar to the one performed here for A. lituratus will help

474 clarify sexual dimorphic trends for other Artibeus species.

475

476

477

478

479

480

481

482

483

484

485

486

487

488

489

490

491

492

493

494

495

496

497

498

499

500

501

502

503

504

505

506

507

508

509

510

511

512

513

514

515

516

517

518

The significant sexual dimorphism found here has implications for behavioral ecology and niche partitioning in the Artibeus species complex. Behavioral differences between sexes have been noted in A. jamaicensis (Kunz \& Diaz, 1995). Males forage primarily near their roosts, allowing them greater time for roost defense, while females forage greater distances and for longer periods of time (Morrison, 1979; Morrison \& Morrison, 1981). These differing strategies may affect cranial morphology. For example, females have the opportunity to seek out higher quality food since they do not have to rely on the food near their roosts. Thus different feeding behaviors in each sex might have an impact on sexual size dimorphism in cases where males and females are feeding on different quality fruits. For example, body mass has been correlated with fruit size in A. jamaicensis and A. lituratus (Ortega \& Castro-Arellano, 2001). Since fruit hardness and skull shape have also been correlated in a wide variety of phyllostomids (Freeman, 2000; Nogueira et al., 2009; Dumont et al., 2012; Hedrick \& Dumont, 2018), these differences may also lead to the sexual shape dimorphism found in the present study's data if males and females choose fruits of different hardnesses. In lateral view, male A. lituratus have a slightly taller, more dome-shaped skull with a more pronounced sagittal crest and shorter rostrum (Fig. 7A), which suggests that they are able to consume somewhat harder fruit given a somewhat higher mechanical advantage for the temporalis muscle. The shape of the zygomatic arch in ventral view is identical in male and female $A$. lituratus indicating no difference in their masseter muscle (Fig. 7B). The presence of a stronger sagittal crest on male skulls leads to the potential hypothesis that male $A$. lituratus are capable of higher bite forces and eating harder fruits than females (Santana et al., 2010), although this needs to be thoroughly evaluated using bite force data. Other alternative hypotheses related to higher sagittal crests in males may include biting during male-male combat or tent-making. Alternative to the functional-related hypothesis that is proposed, sexual selection for larger size in females may play a role in skull shape. Female $A$. lituratus have larger skulls than males (Fig. 7C, D), which is common among bat species where the female is typically larger so she can maintain homeothermy during pregnancy and fly while carrying her pups while they are nursing (Williams and Findley, 1979). Larger size in females may lead to a less developed sagittal crest in comparison with males as they may be able to eat relatively harder foods by virtue of larger body size. More work on potential dietary differences between male and female Artibeus species will need to be done in order to better elucidate these results.

\section{Intraspecific and Geographical Variation in Artibeus lituratus}

Artibeus lituratus has an expansive range from Mexico to Argentina. This study demonstrates substantial geographical variation in A. lituratus skull size and shape with specimens forming country locality clusters in morphospace (Fig. 6A, C). However, the data do not have an obvious pattern of clinal variation, which is demonstrated most clearly by the UPGMA results. In lateral view, two main groups formed using UPGMA of shape data, one containing Peru and Belize, and the other with Paraguay, Argentina, Trinidad, Costa Rica, and the two Mexican localities. The ventral view data had a similar core with the two Mexican localities, Costa Rica, and Trinidad grouping together, but the other country groupings changed (Fig. 6B, D). Belize being outside of the core group of northern countries in spite of being one of the northernmost localities sampled highlights the lack of clinal structure in the shape data. The pairwise results also demonstrate some lack of consensus between the lateral and ventral views

Peer) reviewing PDF | (2020:09:52705:2:0:NEW 21 Jun 2021) 
519 for many countries. For example, Belize is significantly different from all countries other than

520 Costa Rica, Trinidad, and Paraguay in lateral view, but is significantly different from all

521 countries other than Costa Rica and the two Mexican localities in ventral view. In this example,

522 the ventral view suggests a geographical cluster of northern localities, while the lateral view

523 suggests no geographical clustering. Size variation in A. lituratus appears to generate two groups,

524 north and south. Specimens from Belize, Mexico, and Costa Rica had the smallest average

525 centroid sizes among specimens sampled while specimens from Argentina, Trinidad, Peru, and

526 Paraguay had the largest (Table 4). General clinal size variation has been reported in other bats

527 as well (Nargosen \& Tamsitt, 1981; Owen et al., 1984; Storz et al., 2001) and a wide variety of

528 other species (birds, James, 1970; mammals, Koch, 1986; insects, Chown and Gaston, 2010). In

529 spite of this overall grouping, there was no clear clinal pattern within either the northern or

530 southern groups.

531

532

Only in the extreme northern and southern localities did a consistent shape pattern emerge. In lateral view, Argentina is significantly different from all other localities, and in ventral view it is significantly different from all northern localities (Mexico, Belize, Costa Rica), while not significantly different from South American localities (Paraguay, Peru, Trinidad). Similarly, the two Mexican localities are significantly different from all localities other than Costa Rica in lateral view while they are significantly different from all South American localities in ventral view and not different from the other northern localities. This strongly suggests that the $A$. lituratus range only has substantial differences at northern and southern extremes and otherwise does not exhibit a clinally graded morphological spectrum for cranial shape. This demonstrates that analyzing specimens from across a species' range will grant a better understanding of the shape disparity within that taxon, especially in taxa with large ranges such as $A$. lituratus where significantly different morphologies at the extremes of the species' range may be missed.

The lack of an obvious geographical pattern in these data may be due to differences in differences. The present study did not assess environmental variables, but instead looked for general skull shape and size differences in relation to geographical distance. In Eptesicus fuscus, Burnett (1983) found that both climatic factors and geography affected morphology, with geography tending to be a better predictor for wing shape and environment tending to be a better predictor for skull shape. Using linear morphometrics, Marchán-Rivadeneira et al. (2012) found that skull size variation in A. lituratus was tied closely to environmental variables. Factors such as seasonality and precipitation were tightly correlated with skull size. Stevens et al. (2016) examined wing shape variation in A. lituratus in the Atlantic forests of Paraguay and Argentina and found that environmental variables accounted for $75 \%$ of variation across sites. They suggest that this is due to local adaptations in wing morphology, which enhance maneuverability in some environments. Therefore, there may be a larger pattern among bats that both wing shape and cranial shape are more closely tied to environmental factors than geographical distances. Further, taxa in the Amazon are often considered to present more of a mosaic of characters rather than a clear pattern, such as clinal variation (Bates et al., 1998; Ferreira et al., 2014). This may be the case for A. lituratus crania.

Genetic differences across the wide $A$. lituratus range may also have led to the northsouth size differences that are captured in this study. Two subspecies are sometimes recognized (A. lituratus intermedius and A. lituratus palmarus), though are also often considered different at the specific level (A. lituratus and A. intermedius) (Simmons, 2005; Redondo et al., 2008). 
565 Unfortunately, the subspecies identification was not available for the specimens included in this 566 analysis so this could not be assessed. Regardless of subspecies identification, genetic drift may

567 be a factor generating the difference in size between northern and southern specimens of $A$.

568 lituratus as well. Given this study's clear documentation of the range of individual variation

569 present in A. lituratus, a more specific study examining skull shape and size in habitats with

570 different environmental variables in the northern and southern parts of the A. lituratus range

571 would allow for more concrete conclusions.

572

573

574

575

576

577

578

579

580

581

582

583

584

585

586

587

588

589

590

591

592

593

594

595

596

597

598

599

600

601

602

603

604

605

606

607

608

609

\section{Conclusions}

The Artibeus species complex is a widespread, highly diverse lineage, with many species that live in sympatry. Being able to quantify variation and differentiate species morphologically is a step towards understanding the diversification of the Artibeus species complex and the factors that drove its radiation more generally. Morphological variation was not only evident both between the small Artibeus and large Artibeus groups, but fine-scale size and shape variation was also evident within both groups. Shape data were significantly correlated with phylogeny, likely due to the strong clustering of species within the small and large Artibeus groups. Further, given that Artibeus feed on different fruits throughout the year, it is possible that a combination of morphological and behavioral plasticity has led to the modern diversity of the group. This study demonstrated morphological separation between males and females, perhaps due to these behavioral drivers; however, sex accounted for a small percent of total shape variation. Finally, geographical variation is a clear factor governing intraspecific variation in $A$. lituratus. This variation is not obviously driven by clinal factors and likely relates to site-level environmental variables or drift rather than broad geographical distances. Being able to accurately delineate and discriminate among species is critical for both taxonomy and for conservation initiatives (Fernandez et al., 2009) and quantifying inter- and intraspecific variation across a broad geographic range grants insight into how morphological variation in a group is structured, allowing for second-order analyses. Future work on the ecological and behavioral variables that have led to the documented morphological variation among species in Artibeus will help to elucidate the evolution of this successful group of bats.

\section{Acknowledgements}

I thank Jacob Esselstyn (LSU) for access to specimens and help in the Louisiana State University Museum of Natural History collections. I thank Sam Cordero, Andrea D. Rummel (Brown Univ.), V. David Munteanu (Clemson Univ.), and Samantha L. Cox (Univ. of Penn) for comments and insights on earlier versions of this manuscript. I thank Ilse Garcia Romero and Liliana Dávalos (Stony Brook University) for writing and editing the Spanish language abstract. Finally, I thank Daniel Silva (editor), Kara Powder, Fabio Machado, and three anonymous reviewers for reviews that have greatly improved this manuscript.

\section{References}

Adams DC, Otárola-Castillo E. 2013. geomorph: an R package for the collection and analysis of geometric morphometric shape data. Methods in Ecology and Evolution 4:393-399.

Arita HT, Fenton MB. 1997. Flight and echolocation in the ecology and evolution of bats. Trends in Ecology and Evolution 12:53-58. 
610 August PV. 1981. Fig fruit consumption and seed dispersal by Artibeus jamaicensis in the

611

612

613

614

615

616

617

618

619

620

621

622

623

624

625

626

627

628

629

630

631

632

633

634

635

636

637

638

639

640

641

642

643

644

645

646

647

648

649

650

651

652

653

Llanos of Venezuela. Biotropica 13:70-76.

Balseiro F, Mancina CA, Guerrero JA. 2009. Taxonomic status of Artibeus anthonyi (Chiroptera: Phyllostomidae), a fossil bat from Cuba. Journal of Mammalogy 90:14871494.

Bates JM, Hackett SJ, Cracraft J. 1998. Area-relationships in the Neotropical lowlands: an hypothesis based on raw distributions of passerine birds. Journal of Biogeography 25:783-793.

Bookstein FL. 1997. Morphometric tools for landmark data: geometry and biology: Cambridge University Press.

Brosset A, Charles-Dominique P. 1990. The bats from French Guiana: a taxonomic, faunistic and ecological approach. Mammalia 54:509-560.

Burgin CJ, Colella JP, Kahn PL, Upham NS. 2018. How many species of mammals are there? Journal of Mammalogy 99:1-14.

Collyer ML, Sekora DJ, Adams DC. 2015. A method for analysis of phenotypic change for phenotypes described by high-dimensional data. Heredity 115:357-365.

Chown SL, Gaston KJ. 2010. Body size variation in insects: a macroecological perspective. Biological Reviews 85:139-169.

Dumont ER. 1999. The effect of food hardness on feeding behaviour in frugivorous bats (Phyllostomidae): an experimental study. Journal of Zoology 248:219-229.

Dumont ER., O'Neal R. 2004. Food hardness and feeding behavior in Old World fruit bats (Pteropodidae). Journal of Mammalogy 85:8-14.

Dumont ER, Davalos LM, Goldberg A, Santana SE, Rex K, Voigt CC. 2012. Morphological innovation, diversification and invasion of a new adaptive zone. Proceedings of the Royal Society B: Biological Sciences 279:1797-1805.

Dumont ER, Samadevam K, Grosse I, Warsi OM, Baird B, Davalos LM. 2014. Selection for mechanical advantage underlies multiple cranial optima in new world leaf-nosed bats. Evolution 68:1436-1449.

Eisenberg JF, Redford KH. 1989. Mammals of the Neotropics, Volume 3: Ecuador, Bolivia, Brazil: University of Chicago Press.

Ferreira WAS, Borges BdN, Rodrigues-Antunes S, Andrade FAGd, Aguiar GFdS, SilvaJunior JdSe, Marques-Aguiar SA, Harada ML. 2014. Phylogeography of the dark fruit-eating bat Artibeus obscurus in the Brazilian Amazon. Journal of Heredity 105:4859.

Fleming TH. 1986. Opportunism versus specialization: the evolution of feeding strategies in frugivorous bats. Frugivores and seed dispersal: Springer, 105-118.

Freeman PW. 2000. Macroevolution in Microchiroptera: recoupling morphology and ecology with phylogeny. Mammalogy Papers: University of Nebraska State Museum:8.

Galetti M, Morellato L. 1994. Diet of the large fruit-eating bat Artibeus lituratus in a forest fragment in Brasil. Mammalia 58:661-664.

Guerrero JA, De Luna E, Sánchez-Hernández C. 2003. Morphometrics in the quantification of character state identity for the assessment of primary homology: an analysis of character variation of the genus Artibeus (Chiroptera: Phyllostomidae). Biological Journal of the Linnean Society 80:45-55.

Peer] reviewing PDF | (2020:09:52705:2:0:NEW 21 Jun 2021) 
654 Hedrick BP, Cordero SA, Zanno LE, Noto C, Dodson P. 2019. Quantifying shape and

655

656

657

658

659

660

661

662

663

664

665

666

667

668

669

670

671

672

673

674

675

676

677

678

679

680

681

682

683

684

685

686

687

688

689

690

691

692

693

694

695

696

697

698

699 ecology in avian pedal claws: The relationship between the bony core and keratinous sheath. Ecology and Evolution 9:11545-11556.

Hedrick BP, Dickson BV, Dumont ER, Pierce SE. 2020. The evolutionary diversity of locomotor innovation in rodents is not linked to proximal limb morphology. Scientific Reports 10:1-11.

Hedrick BP, Dumont ER. 2018. Putting the leaf-nosed bats in context: a geometric morphometric analysis of three of the largest families of bats. Journal of Mammalogy 99:1042-1054.

Hedrick BP, Mutumi GL, Munteanu VD, Sadier A, Davies KT, Rossiter SJ, Sears KE, Dávalos LM, Dumont E. 2019. Morphological diversification under high integration in a hyper diverse mammal clade. Journal of Mammalian Evolution:1-13.

James FC. 1970. Geographic size variation in birds and its relationship to climate. Ecology 51:365-390.

Jones KE, Bininda-Emonds OR, Gittleman JL. 2005. Bats, clocks, and rocks: diversification patterns in Chiroptera. Evolution 59:2243-2255.

Kay EH, Hoekstra HE. 2008. Rodents. Current Biology 18:R406-410.

Koch PL. 1986. Clinal geographic variation in mammals: implications for the study of chronoclines. Paleobiology 12:269-281.

Kunz TH, Diaz CA. 1995. Folivory in fruit-eating bats, with new evidence from Artibeus jamaicensis (Chiroptera: Phyllostomidae). Biotropica 27:106-120.

Larsen PA, Marchán-Rivadeneira MR, Baker RJ. 2010. Natural hybridization generates mammalian lineage with species characteristics. Proceedings of the National Academy of Sciences 107:11447-11452.

Lim BK. 1997. Morphometric differentiation and species status of the Allopatric fruit-eating bats Artibeus jamaicensis and A. planirostris in Venezuela. Studies on Neotropical Fauna and Environment 32:65-71.

Lim BK, Engstrom MD, Patton JC, Bickham JW. 2008. Systematic review of small fruiteating bats (Artibeus) from the Guianas, and a re-evaluation of A. glaucus bogotensis. Acta Chiropterologica 10:243-256.

Machado FA, Zahn TMG, Marroig G. 2018. Evolution of morphological integration in the skull of Carnivora (Mammalia): Changes in Canidae lead to increased evolutionary potential of facial traits. Evolution 72:1399-1419.

Marchan-Rivadeneira MR, Larsen PA, Phillips CJ, Strauss RE, Baker RJ. 2012. On the association between environmental gradients and skull size variation in the great fruiteating bat, Artibeus lituratus (Chiroptera: Phyllostomidae). Biological Journal of the Linnean Society 105:623-634.

Marchán-Rivadeneira MR, Phillips CJ, Strauss RE, Guerrero JA, Mancina CA, Baker RJ. 2010. Cranial differentiation of fruit-eating bats (genus Artibeus) based on sizestandardized data. Acta Chiropterologica 12:143-154.

Morales AE, Ruedi M, Field K, Carstens BC. 2019. Diversification rates have no effect on the convergent evolution of foraging strategies in the most speciose genus of bats, Myotis. Evolution 73:2263-2280.

Moore TY, Organ CL, Edwards SV, Biewener AA, Tabin CJ, Jenkins Jr FA, Cooper KL. 2015. Multiple phylogenetically distinct events shaped the evolution of limb skeletal morphologies associated with bipedalism in the jerboas. Current Biology 25:2785-2794.

Peer] reviewing PDF | (2020:09:52705:2:0:NEW 21 Jun 2021) 
700

701

702

703

704

705

706

707

708

709

710

711

712

713

714

715

716

717

718

719

720

721

722

723

724

725

726

727

728

729

730

731

732

733

734

735

736

737

738

739

740

741

742

743

744

745

Morrison DW. 1979. Apparent male defense of tree hollows in the fruit bat, Artibeus jamaicensis. Journal of Mammalogy 60:11-15.

Morrison DW, Morrison SH. 1981. Economics of harem maintenance by a neotropical bat. Ecology 62:864-866.

Mutanen M, Pretorius E. 2007. Subjective visual evaluation vs. tradition and geometric morphometrics in species delimitation: a comparison of moth genitalia. Systematic Entomology 32:371-386.

Nagorsen D, Tamsitt J. 1981. Systematics of Anoura cultrata, A. brevirostrum, and $A$. werckleae. Journal of Mammalogy 62:82-100.

Nogueira MR, Peracchi AL, Monteiro LR. 2009. Morphological correlates of bite force and diet in the skull and mandible of phyllostomid bats. Functional Ecology 23:715-723.

Ortega J, Castro-Arellano I. 2001. Artibeus jamaicensis. Mammalian Species:1-9.

Owen J, Schmidly D, Davis W. 1984. A morphometric analysis of three species of Carollia (Chiroptera, Glossophaginae) from Middle America. Mammalia 48:85-94.

Perez SI, Bernal V, Gonzalez PN. 2006. Differences between sliding semi-landmark methods in geometric morphometrics, with an application to human craniofacial and dental variation. Journal of Anatomy 208:769-784.

R Core Development Team. 2019. $R$ : A language and environment for statistical computing. $R$ Foundation for Statistical Computing, Vienna, Austria.

Redondo RA, Brina LP, Silva RF, Ditchfield AD, Santos FR. 2008. Molecular systematics of the genus Artibeus (Chiroptera: Phyllostomidae). Molecular Phylogenetics and Evolution 49:44-58.

Rohlf F. 2006. tpsDig, version 2.10. http://life bio sunysb edu/morph/index html.

Rojas D, Warsi OM, Dávalos LM. 2016. Bats (Chiroptera: Noctilionoidea) challenge a recent origin of extant neotropical diversity. Systematic Biology 65:432-448.

Samuels JX, Van Valkenburgh B. 2008. Skeletal indicators of locomotor adaptations in living and extinct rodents. Journal of Morphology 269:1387-1411.

Santana SE, Dumont ER, Davis JL. 2010. Mechanics of bite force production and its relationship to diet in bats. Functional Ecology 24:776-784.

Santana SE, Lofgren S. 2013. Does nasal echolocation influence the modularity of the mammal skull? Journal of Evolutionary Biology 26:2520-2526.

Shi JJ, Rabosky DL. 2015. Speciation dynamics during the global radiation of extant bats. Evolution 69:1528-1545.

Simmons NB, Voss RS. 1998. The mammals of Paracou, French Guiana, a Neotropical lowland rainforest fauna. Part 1, Bats. Bulletin of the AMNH:237.

Sneath PH, Sokal RR. 1973. Numerical taxonomy. The principles and practice of numerical classification.

Stevens RD, Johnson ME, McCulloch ES. 2016. Geographic variation of wing morphology of great fruit-eating bats (Artibeus lituratus): environmental, genetic and spatial correlates of phenotypic differences. Biological Journal of the Linnean Society 118:734-744.

Storz JF, Balasingh J, Bhat HR, Nathan PT, Doss DPS, Prakash AA, Kunz TH. 2001. Clinal variation in body size and sexual dimorphism in an Indian fruit bat, Cynopterus sphinx (Chiroptera: Pteropodidae). Biological Journal of the Linnean Society 72:17-31.

Swanson HK, Lysy M, Power M, Stasko AD, Johnson JD, Reist JD. 2015. A new probabilistic method for quantifying n-dimensional ecological niches and niche overlap. Ecology 96:318-324.

Peer] reviewing PDF | (2020:09:52705:2:0:NEW 21 Jun 2021) 
746

747

748

749

750

751

752

753

754

755

756

Vander Linden A, Hedrick BP, Kamilar JM, Dumont ER. 2019. Atlas morphology, scaling and locomotor behaviour in primates, rodents and relatives (Mammalia: Euarchontoglires). Zoological Journal of the Linnean Society 185:283-299.

Williams DF, Findley JS. 1979. Sexual size dimorphism in vespertilionid bats. The American Midland Naturalist 102:113-126.

Zelditch ML, Swiderski DL, Sheets HD. 2012. Geometric morphometrics for biologists: a primer: Academic Press.

Zortea M, Mendes SL. 1993. Folivory in the big fruit-eating bat, Artibeus lituratus (Chiroptera: Phyllostomidae) in eastern Brazil. Journal of Tropical Ecology 9:117-120. 


\section{Tables:}

758

759 Table 1: Lateral view Procrustes ANOVA assessing the relationship between shape, species, sex, and $\log 10$-transformed centroid size (Shape $\sim$ Species $*$ Sex $*$ Size). Bolded values represent significant $\mathrm{p}$-values at $\alpha=0.05$. Df - degrees of freedom. SS - sum of squares. MS - mean squares.

763

Table 2: Ventral view Procrustes ANOVA assessing the relationship between shape, species, sex, and $\log 10$-transformed centroid size (Shape $\sim$ Species $*$ Sex $*$ Size). Bolded values represent significant $\mathrm{p}$-values at $\alpha=0.05$. Df - degrees of freedom. SS - sum of squares. MS - mean

767

768 squares.

Table 3: Pairwise comparison p-values between countries for the A. lituratus data (lateral view above diagonal, ventral view below diagonal). (Shape $\sim$ Sex + Size + Country). Arg $=$ Argentina, Bel $=$ Belize, Cos $=$ Costa Rica, Col = Mexico, Colima, Tab = Mexico, Tabasco, Par = Paraguay, Per $=$ Peru, Tri $=$ Trinidad. Bolded values represent significant $p$-values at $\alpha=0.05$. Z-scores are presented in Table S6 for both lateral and ventral views.

Table 4: Average centroid sizes for A. lituratus specimens by country with smallest values at the 777 top and largest at the bottom. The order for the lateral view and ventral view is identical.

778

779

780 
781

782

783

784

785

786

787

788

789

790

791

792

793

794

795

796

797

798

799

800

801

802

803

804

805

806

807

808

809

810

811

812

813

814

815

816

817

818

819

\section{Figure Captions:}

Figure 1: Phylogeny of the Artibeus species complex. Representative skulls shown in lateral view with scale bars. Scale $=50 \mathrm{~mm}$. Each skull has its respective species code used in figures 3 and 4 (e.g., $\mathrm{Aj}=$ Artibeus jamaicensis). Colored shapes correspond to species in figures 3 and 4. Large Artibeus are represented by triangles and small Artibeus are represented by circles. The phylogeny was generated based on Rojas et al. (2016).

Figure 2: Landmark configuration for specimens in (A) lateral and (B) ventral views. Numbered circles correspond to landmarks while red lines correspond to evenly spaced semilandmark curves. See Table S1 for landmark definitions. Scale $=50 \mathrm{~mm}$.

Figure 3: Principal component analyses of the Artibeus species complex in (A) lateral view and (B) ventral view. Thin-plate spline grids represent shape change along principal component 1 and 2. Colors and species codes refer to individual taxa within the Artibeus species complex and are derived from figure 1.

Figure 4: Evolutionary allometric trajectories for specimens of the Artibeus species complex in (A) lateral view and $(C)$ ventral view. These plots show the common allometric component (CAC) of shape (y-axis) plotted against the log10-transformed centroid size (x-axis). Centroid size violin plots for (B) lateral view and (D) ventral view. Colors and species codes refer to individual taxa within the Artibeus species complex and are derived from figure 1.

Figure 5: Map of Mexico, Central, and South America highlighting countries where samples of $\boldsymbol{A}$. lituratus were taken. Representative skulls shown in lateral view with scale bars. Scale $=50 \mathrm{~mm}$. Colored circles around skulls and countries correspond to colors used to identify countries in figure 6.

Figure 6: Principal component analyses for $A$. lituratus subset in (A) lateral view and (C) ventral view. UPGMA cluster plots for (B) lateral view and (D) ventral view. Colors refer to countries where A. lituratus specimens were collected and are derived from figure 5 . Southern localities (Argentina, Paraguay, Peru, Trinidad) are inverted triangles while northern localities (Mexico, Belize, Costa Rica) are squares.

Figure 7: Comparison of male and female shape and size in lateral $(A, C)$ and ventral $(B$, D) views. For shape wireframes, males are gray and females are black. Wireframes are magnified by three times to accentuate differences, though these differences are quite minor in general. 
820 Table S1: Landmark definitions. Landmark number, type (according to Bookstein's topology of

821

822

823

824

825

826

827

828

829

830

831

832

833

834

835

836

837

838

839

840

841

842

843

844

845

846

847

848

849

850

851

852

853

854

855

856

857

858

859

860

861

862

863

864

865

landmarks), and a description of the landmark in anatomical terms.

Table S2: Interspecific data including taxon name, specimen number, locality, sex, principal component scores for PC1-4 in lateral and ventral views, centroid sizes in lateral and ventral views, and common allometric coefficient scores in lateral and ventral views.

Table S3: Interspecific statistical analyses. Results for lateral and ventral view Procrustes ANOVAs of shape and size; shape, species, sex, and size; and size, species, and sex. Tests of phylogenetic signal in lateral and ventral view for shape and size.

Table S4: Interspecific data for species means used in phylogenetic signal analyses including species names, centroid sizes, and PC1-4 scores for lateral and ventral view.

Table S5: Intraspecific data for A. lituratus including specimen number, locality, sex, country of origin, principal component scores for PC1-4 in lateral and ventral views, and centroid sizes in lateral and ventral views.

Table S6: Intraspecific statistical analyses for A. lituratus. Results for lateral and ventral view Procrustes ANOVAs of shape, sex, size, and country with pairwise comparisons. Distance matrices for country means, and the cophenetic coefficients for lateral and ventral datasets are also included.

Figure S1: Principal component analyses of the (A) lateral and (B) ventral views showing multiple replicates of one specimen. To assess error in the data, one specimen was selected at random and landmarked 10 times. That specimen (red) was then plotted in PC morphospace with all other specimens (gray) demonstrating minimal within individual landmarking error compared to between individual differences.

\section{Figure S2: Colorblind friendly principal component analyses of the Artibeus species} complex in (A) lateral view and (B) ventral view. Thin-plate spline grids represent shape change along principal component 1 and 2. Shapes and species codes refer to individual taxa within the Artibeus species complex. Species codes refer to figure 1 and shapes are shown next to species codes within the figure.

Figure S3: Niche overlap results for the lateral dataset. $X$-axis shows the probability $(1-100)$ of niche overlap of the species in the row versus the species in the column. The solid vertical turquoise line represents the mean probability and the hashed vertical turquoise lines represent the $95 \%$ confidence intervals. For species pairs where the mean is 0 , there is no overlap between species. Aan $=$ Artibeus anderseni, Aaz $=$ A. aztecus, Aci $=$ A. cinereus, $\mathrm{Afi}=A$. fimbriatus, Afr $=\mathrm{A}$. fraterculus, $\mathrm{Aj}=A$. jamaicensis, $\mathrm{Al}=$ A. lituratus, $\mathrm{Ao}=A$. obscurus, $\mathrm{Aph}=A$. phaeotis, $\mathrm{Apl}=$ A. planirostris, $\mathrm{At}=$ A. toltecus.

Figure S4: Niche overlap results for the ventral dataset. $X$-axis shows the probability (1-100) of niche overlap of the species in the row versus the species in the column. The solid vertical turquoise line represents the mean probability and the hashed vertical turquoise lines represent

Peer) reviewing PDF | (2020:09:52705:2:0:NEW 21 Jun 2021) 
866 the $95 \%$ confidence intervals. For species pairs where the mean is 0 , there is no overlap between 867 species. Aan $=$ Artibeus anderseni, $\mathrm{Aaz}=$ A. aztecus, Aci $=$ A. cinereus, Afi $=$ A. fimbriatus, Afr

$868=\mathrm{A}$. fraterculus, $\mathrm{Aj}=A$. jamaicensis, $\mathrm{Al}=A$. lituratus, $\mathrm{Ao}=A$. obscurus, $\mathrm{Aph}=A$. phaeotis, 869 Apl $=$ A. planirostris, At $=$ A. toltecus .

870

871 Figure S5: Phylomorphospace and disparity through time. Principal component

872 morphospaces (PC1 x PC2) for species means in (A) lateral and (B) ventral views with the

873 species phylogeny from Rojas et al. (2016) plotted on top of points. White circles represent 874 nodes on the phylogeny. Colors correspond to species colors in figure 1 of the main text.

875 Disparity through time analyses for (C) lateral and (D) ventral views. Solid line represents

876 observed data while dotted line represents Brownian motion. Both views show an increase in

877 disparity at $\sim 5$ mya at the split between the small and large Artibeus.

878

879

880

881 File S2: TPS file for interspecific dataset in ventral view.

882

883 File S3: TPS file for intraspecific dataset (just A. lituratus) in lateral view.

884

885 File S4: TPS file for intraspecific dataset (just A. lituratus) in ventral view.

886

887 
Figure 1

Figure 1: Phylogeny of the Artibeus species complex.

Representative skulls shown in lateral view with scale bars. Scale $=50 \mathrm{~mm}$. Each skull has its respective species code used in figures 3 and 4 (e.g., Aj = Artibeus jamaicensis). Colored shapes correspond to species in figures 3 and 4. Large Artibeus are represented by triangles and small Artibeus are represented by circles. The phylogeny was generated based on Rojas et al. (2016). 


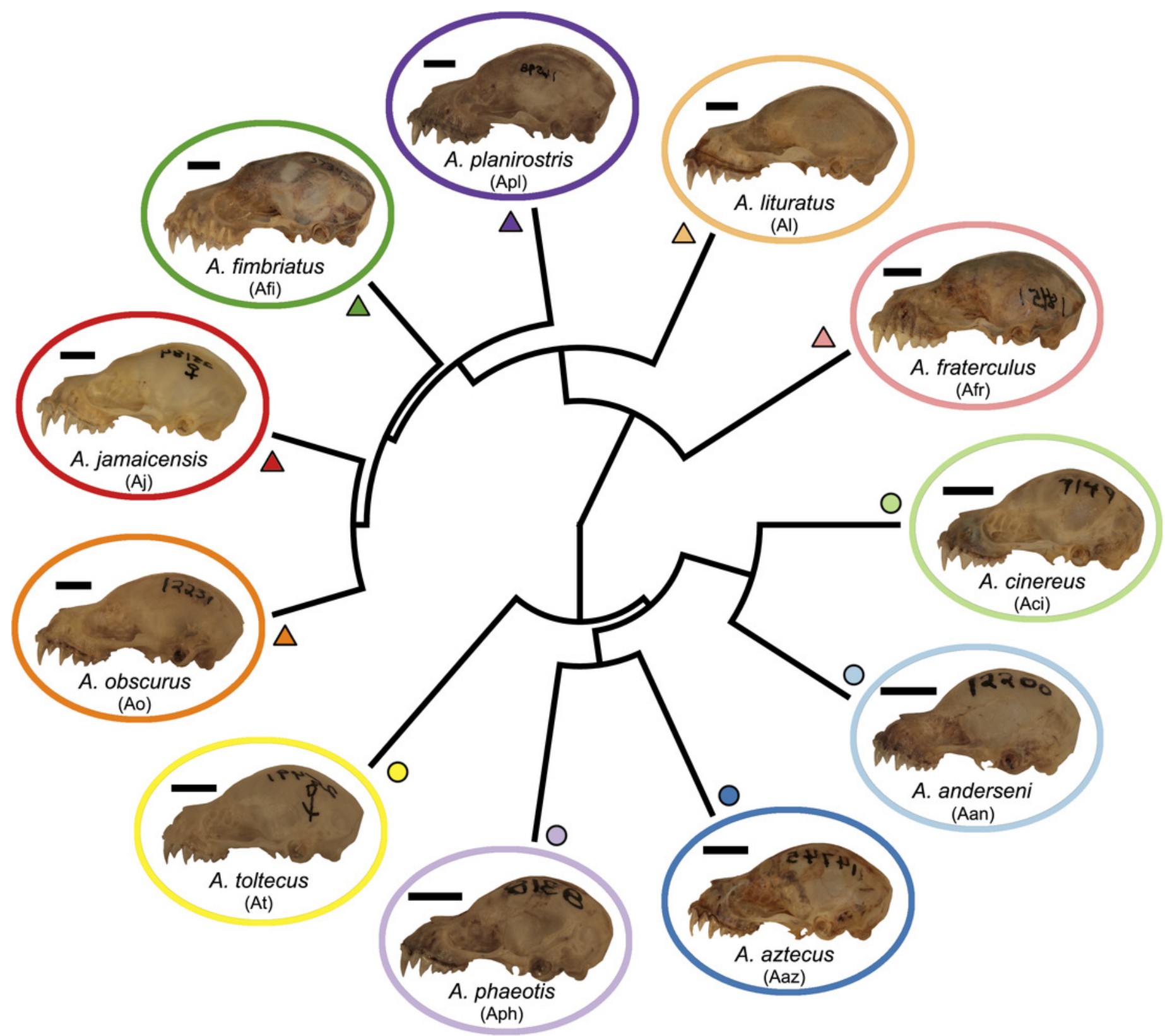


Figure 2

Figure 2: Landmark configuration for specimens in (A) lateral and (B) ventral views. Numbered circles correspond to landmarks while red lines correspond to semi-landmark curves. See Table S1 for landmark definitions. Scale $=50 \mathrm{~mm}$. 


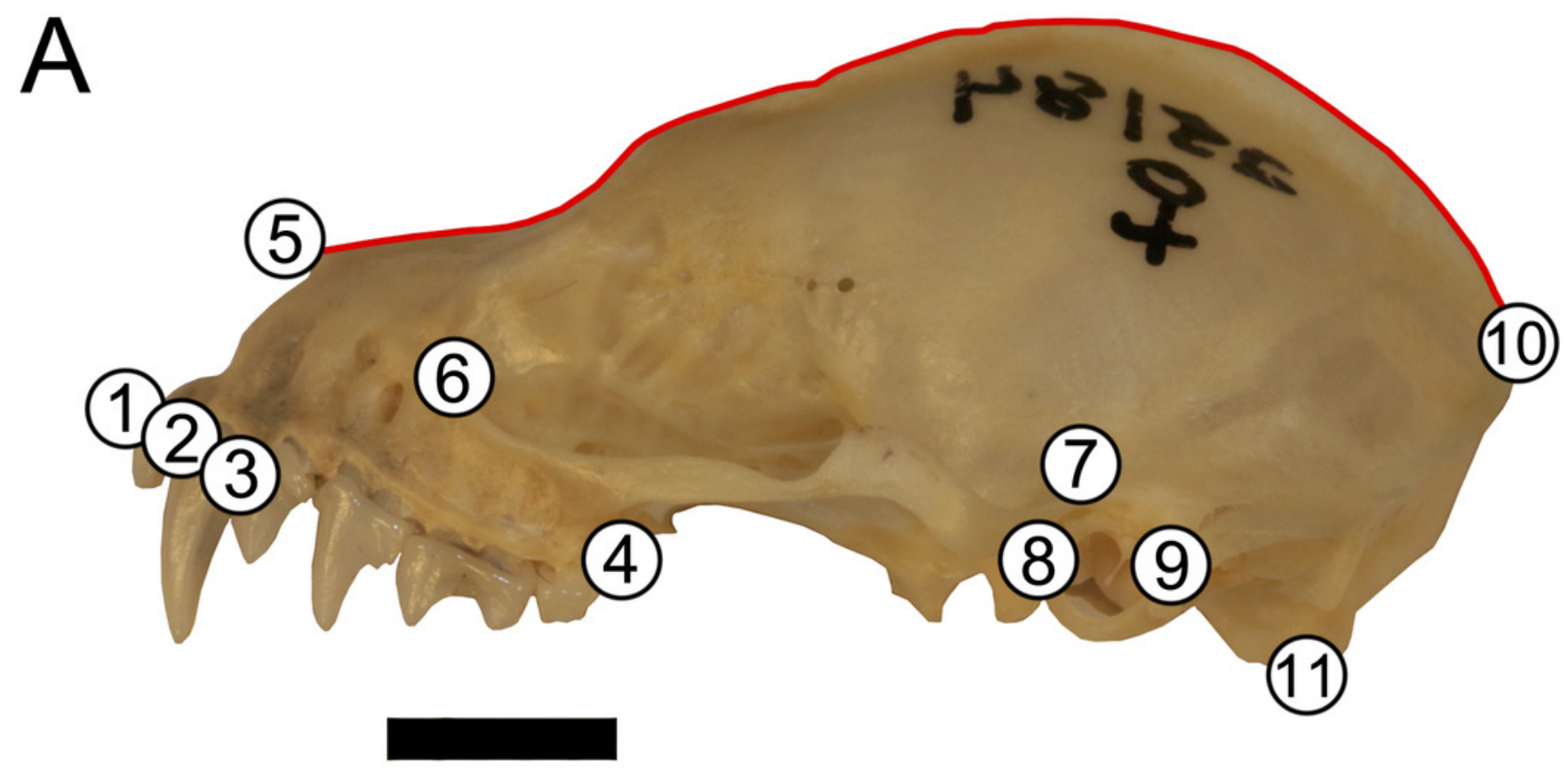

B

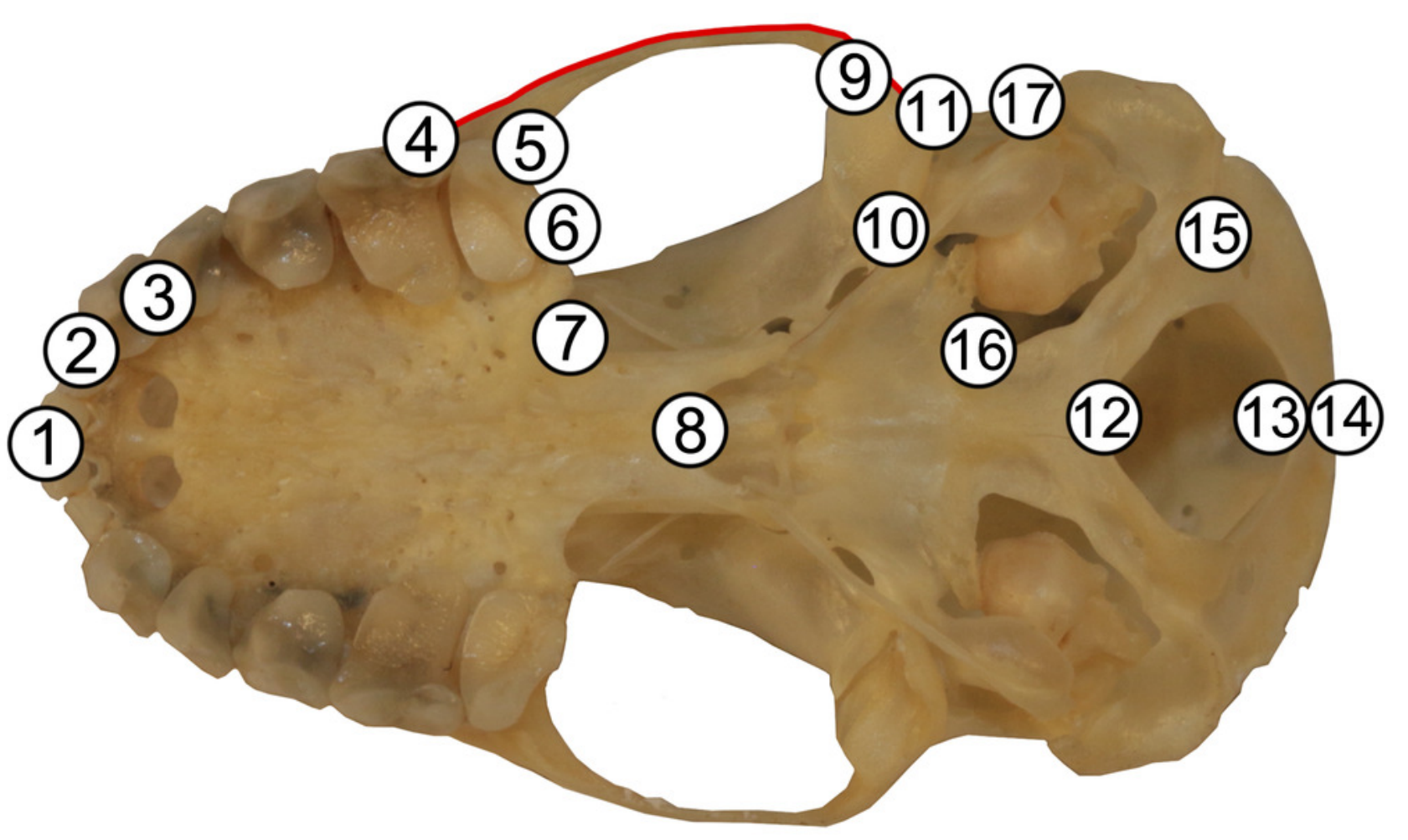


Figure 3

Figure 3: Principal component analyses of the Artibeus species complex in (A) lateral view and (B) ventral view.

Thin-plate spline grids represent shape change along principal component 1 and 2. Colors and species codes refer to individual taxa within the Artibeus species complex and are derived from figure 1. 

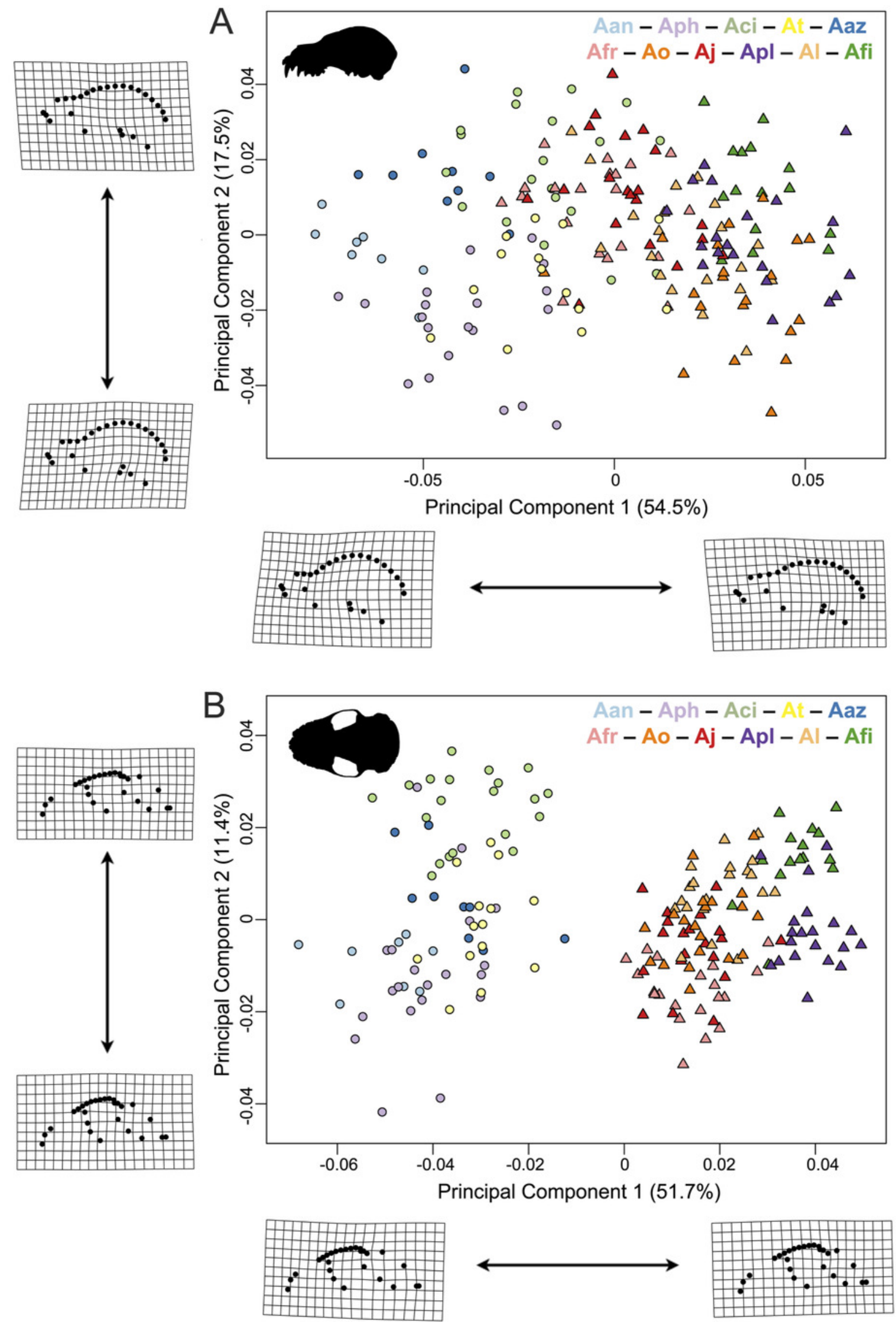
Figure 4

Figure 4: Evolutionary allometric trajectories for specimens of the Artibeus species complex in (A) lateral view and (C) ventral view.

These plots show the common allometric component (CAC) of shape (y-axis) plotted against the log10-transformed centroid size (x-axis). Centroid size box plots for (B) lateral view and (D) ventral view. Colors and species codes refer to individual taxa within the Artibeus species complex and are derived from figure 1. 

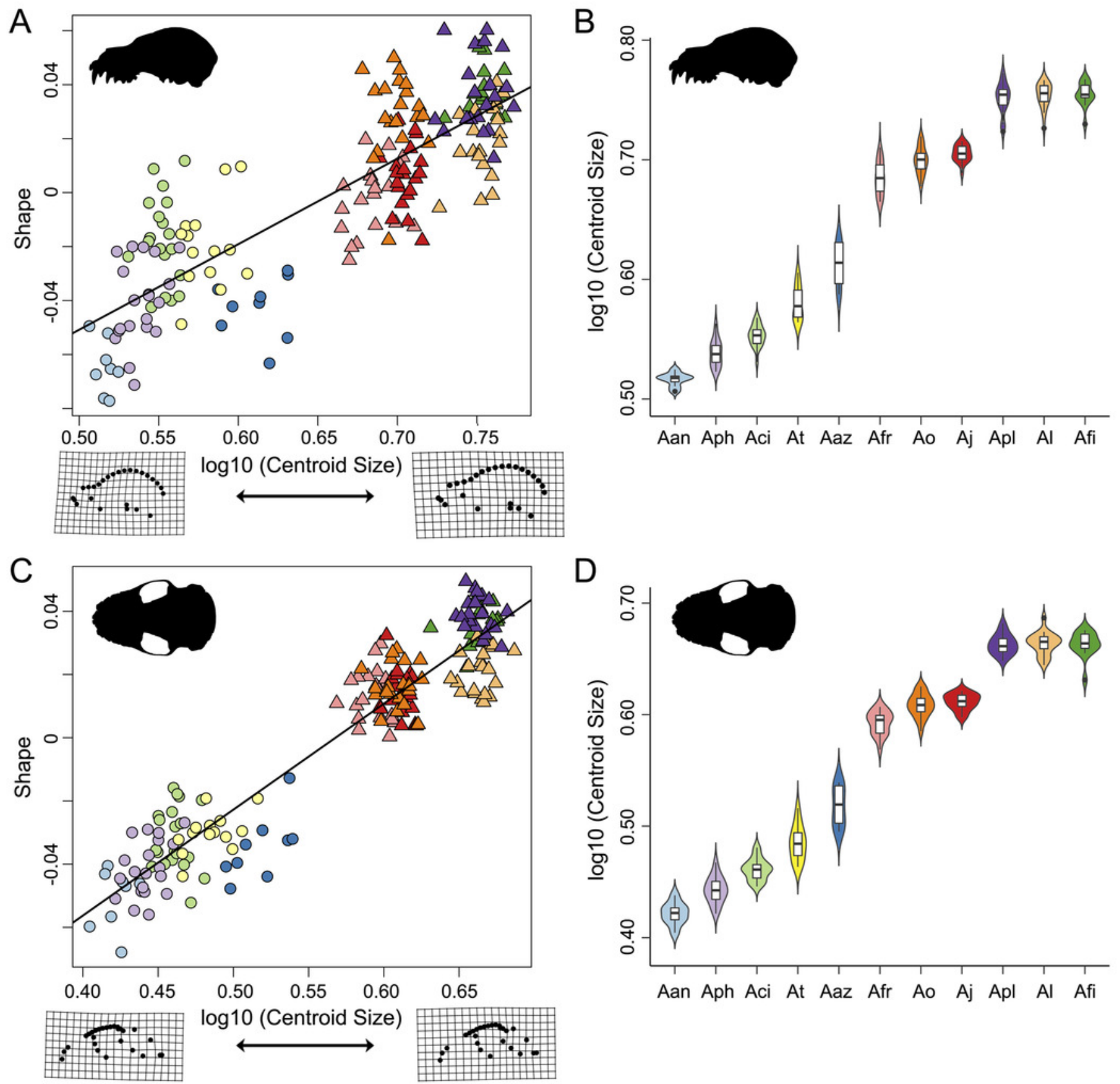


\section{Figure 5}

Figure 5: Map of Mexico, Central, and South America highlighting countries where samples of $A$. lituratus were taken.

Representative skulls shown in lateral view with scale bars. Scale $=50 \mathrm{~mm}$. Colored circles around skulls and countries correspond to colors used to identify countries in figure 6 . 


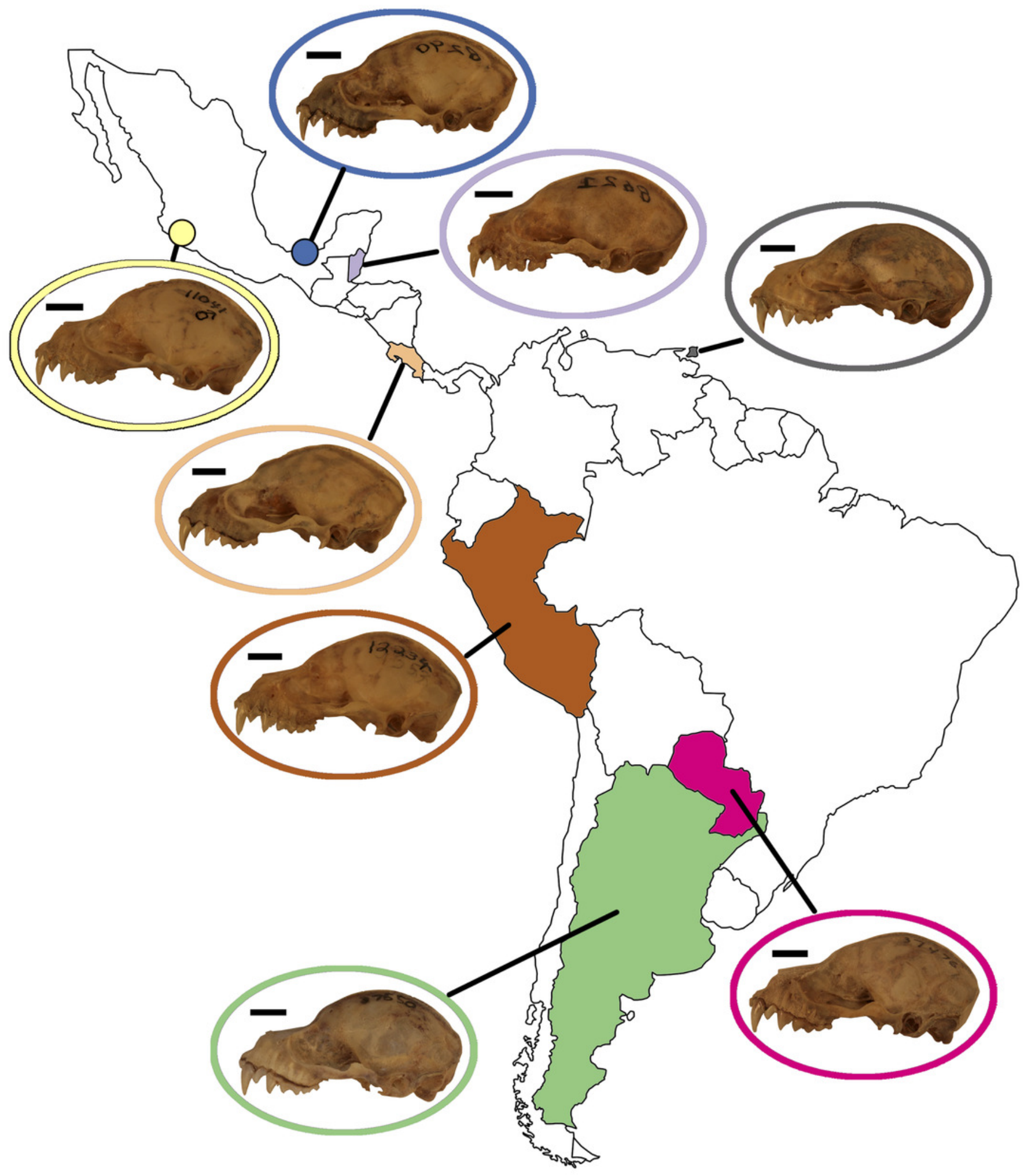


Figure 6

Figure 6: Principal component analyses for $A$. lituratus subset in (A) lateral view and (C) ventral view. UPGMA cluster plots for (B) lateral view and (D) ventral view.

Colors refer to countries where $A$. lituratus specimens were collected and are derived from figure 5. Southern localities (Argentina, Paraguay, Peru, Trinidad) are inverted triangles while northern localities (Mexico, Belize, Costa Rica) are squares.
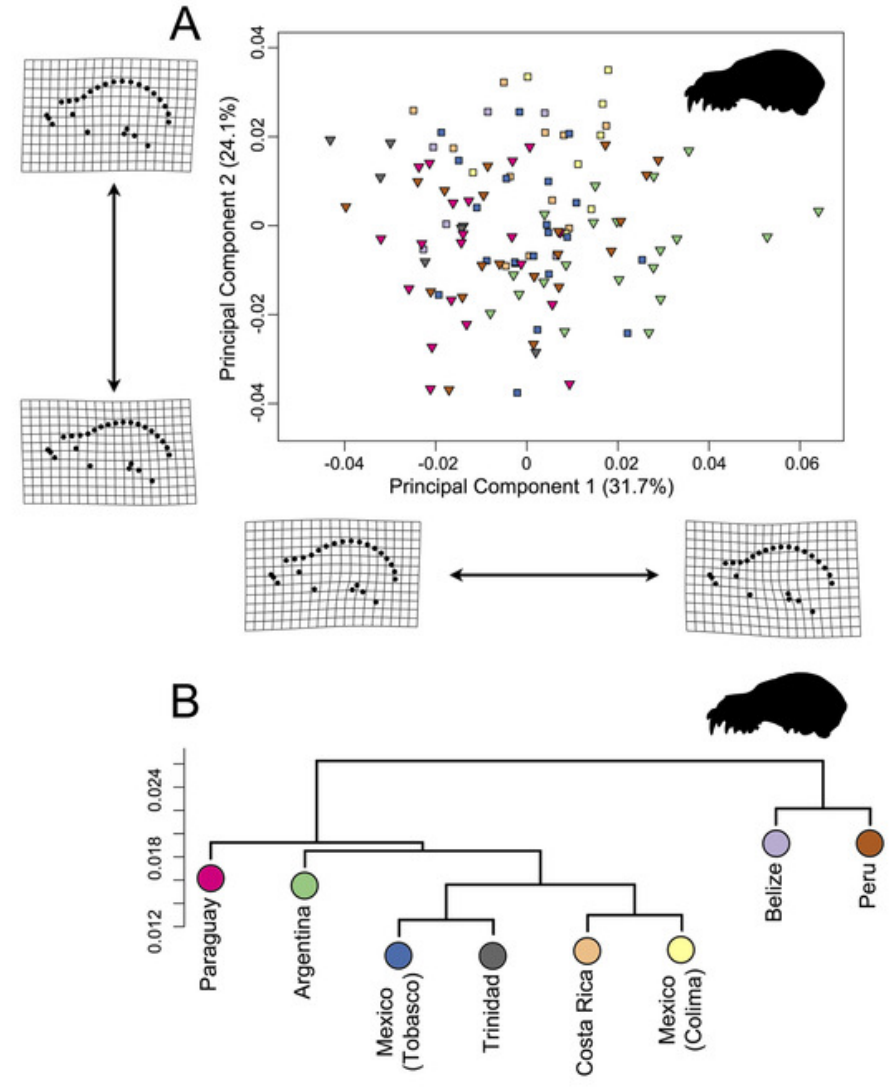
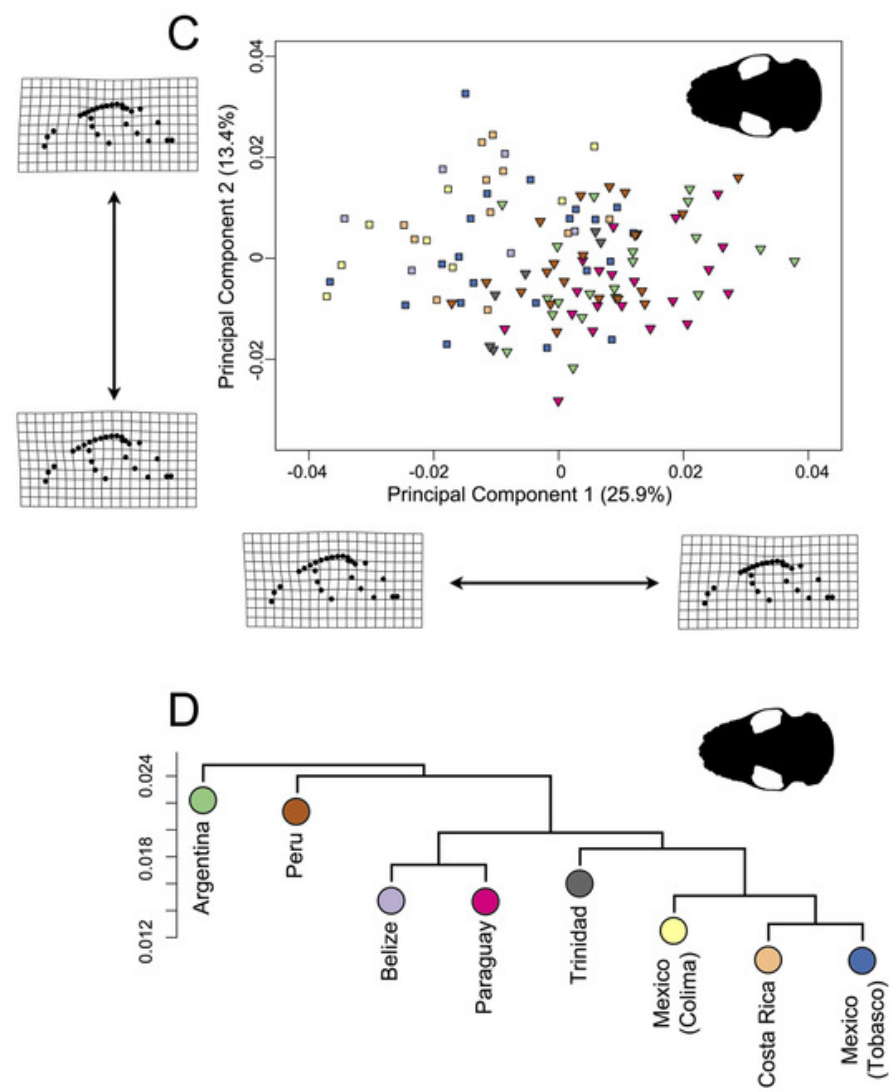
Figure 7

Figure 7: Comparison of male and female shape and size in lateral $(A, C)$ and ventral ( $B$, D) views.

For shape wireframes, males are gray and females are black. Wireframes are magnified by three times to accentuate differences, though these differences are quite minor in general.

A

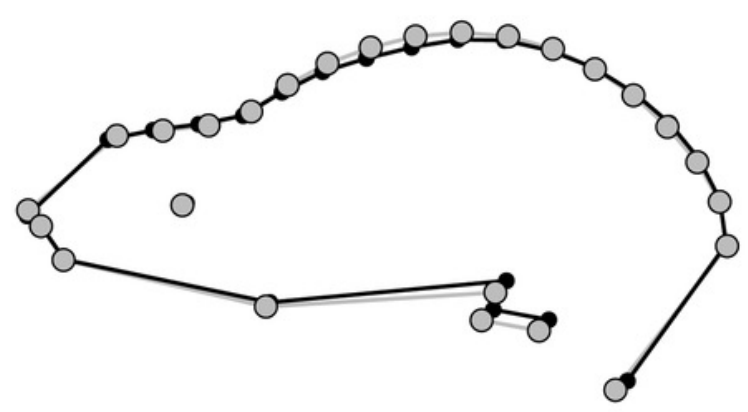

C

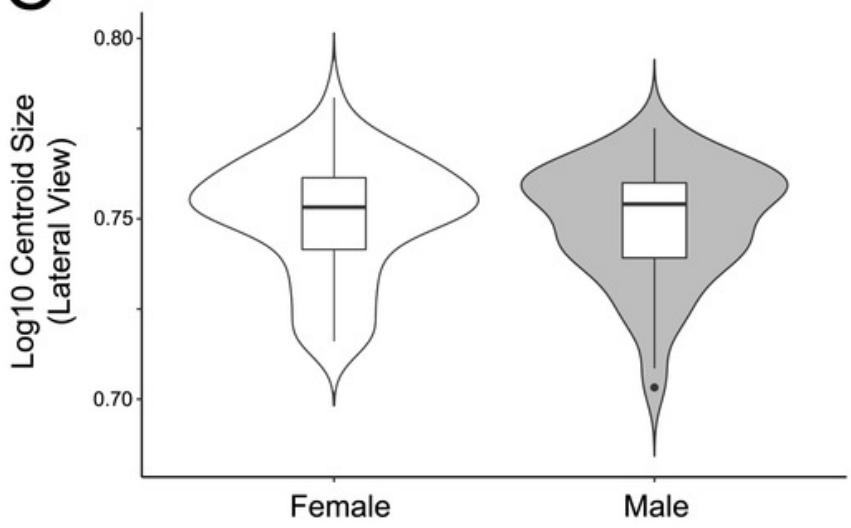

B

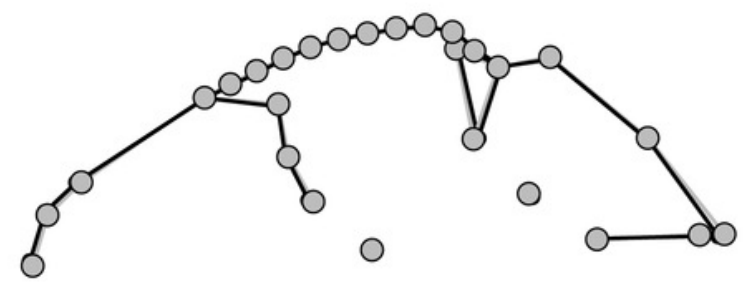

D

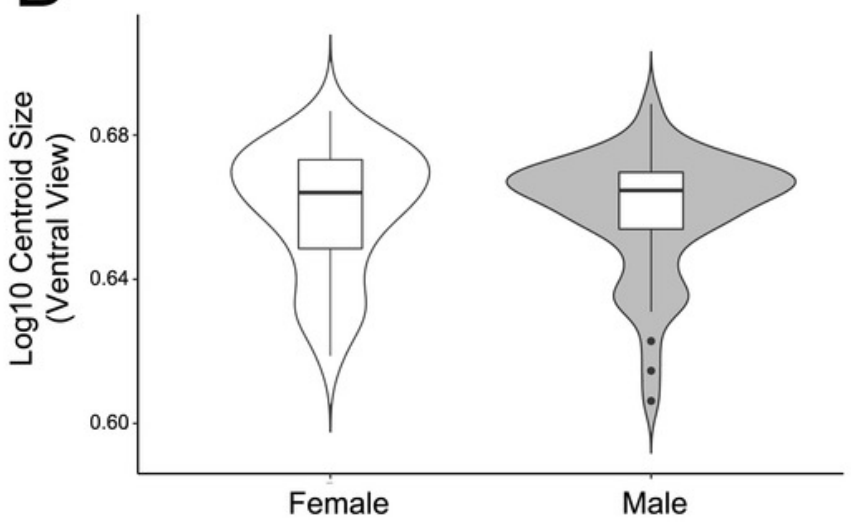




\section{Table 1 (on next page)}

Lateral view Procrustes ANOVA assessing the relationship between shape, species, sex, and $\log 10$-transformed centroid size (Shape $\sim$ Species $*$ Sex $*$ Size). Bolded values represent significant $p$-values at $a=0.05$. Df - degrees of freedom. SS - sum of square 
1 Table 1: Lateral view Procrustes ANOVA assessing the relationship between shape, species, 2 sex, and $\log 10$-transformed centroid size (Shape $\sim$ Species * Sex * Size). Bolded values

3 represent significant $\mathrm{p}$-values at $\alpha=0.05$. Df - degrees of freedom. SS - sum of squares. MS 4 mean squares.

5

\begin{tabular}{|l|c|c|c|c|c|c|c|}
\hline & Df & SS & $\mathrm{MS}$ & $\mathrm{R}^{2}$ & $\mathrm{~F}$ & $\mathrm{Z}$ & $\mathrm{p}$ \\
\hline Species & 10 & 0.228 & 0.023 & 0.605 & 28.058 & 12.092 & $\mathbf{0 . 0 0 1}$ \\
Sex & 1 & 0.003 & 0.003 & 0.009 & 4.184 & 4.654 & $\mathbf{0 . 0 0 1}$ \\
Size & 1 & 0.004 & 0.004 & 0.010 & 4.521 & 5.040 & $\mathbf{0 . 0 0 1}$ \\
Species:Sex & 10 & 0.010 & 0.001 & 0.026 & 1.183 & 6.596 & $\mathbf{0 . 0 0 1}$ \\
Species:Size & 10 & 0.010 & 0.001 & 0.026 & 1.197 & 6.733 & $\mathbf{0 . 0 0 1}$ \\
Sex:Size & 1 & 0.000 & 0.000 & 0.000 & 0.133 & -1.405 & 0.919 \\
Species:Sex:Size & 10 & 0.007 & 0.001 & 0.018 & 0.841 & 5.441 & $\mathbf{0 . 0 0 1}$ \\
Residuals & 142 & 0.115 & 0.001 & 0.306 & & & \\
Total & 185 & 0.377 & & & & & \\
\hline
\end{tabular}

6 


\section{Table 2 (on next page)}

Table 2: Ventral view Procrustes ANOVA assessing the relationship between shape, species, sex, and log10-transformed centroid size (Shape $\sim$ Species * Sex * Size). Bolded values represent significant $p$-values at $\alpha=0.05$. Df - degrees of freedom. SS sum 
1 Table 2: Ventral view Procrustes ANOVA assessing the relationship between shape, species, 2 sex, and $\log 10$-transformed centroid size (Shape $\sim$ Species * Sex * Size). Bolded values

3 represent significant $\mathrm{p}$-values at $\alpha=0.05$. Df - degrees of freedom. SS - sum of squares. MS 4 mean squares.

5

\begin{tabular}{|l|c|c|c|c|c|c|c|}
\hline & Df & SS & $M S$ & $\mathrm{R}^{2}$ & $\mathrm{~F}$ & $\mathrm{Z}$ & $\mathrm{p}$ \\
\hline Species & 10 & 0.220 & 0.022 & 0.630 & 31.324 & 13.058 & $\mathbf{0 . 0 0 1}$ \\
Sex & 1 & 0.001 & 0.001 & 0.002 & 1.149 & 3.081 & $\mathbf{0 . 0 0 1}$ \\
Size & 1 & 0.003 & 0.003 & 0.010 & 4.922 & 6.701 & $\mathbf{0 . 0 0 1}$ \\
Species:Sex & 10 & 0.008 & 0.001 & 0.023 & 1.151 & 9.060 & $\mathbf{0 . 0 0 1}$ \\
Species:Size & 10 & 0.010 & 0.001 & 0.027 & 1.366 & 10.198 & $\mathbf{0 . 0 0 1}$ \\
Sex:Size & 1 & 0.001 & 0.001 & 0.002 & 0.915 & 3.091 & $\mathbf{0 . 0 0 3}$ \\
Species:Sex:Size & 10 & 0.007 & 0.001 & 0.020 & 0.970 & 8.133 & $\mathbf{0 . 0 0 1}$ \\
Residuals & 142 & 0.100 & 0.001 & 0.286 & & & \\
Total & 185 & 0.350 & & & & & \\
\hline
\end{tabular}

6 


\section{Table 3 (on next page)}

Table 3: Pairwise comparison $p$-values between countries for the A. lituratus data (lateral view above diagonal, ventral view below diagonal). (Shape $\sim$ Sex + Size + Country). Arg = Argentina, Bel = Belize, Cos = Costa Rica, Col = Mexico, Colima, Tab 
1 Table 3: Pairwise comparison p-values between countries for the A. lituratus data (lateral view 2 above diagonal, ventral view below diagonal). (Shape $\sim$ Sex + Size + Country). Arg = Argentina, $3 \mathrm{Bel}=$ Belize, $\mathrm{Cos}=$ Costa Rica, $\mathrm{Col}=$ Mexico, Colima, $\mathrm{Tab}=$ Mexico, Tabasco, $\mathrm{Par}=$ Paraguay, 4 Per $=$ Peru, Tri $=$ Trinidad. Bolded values represent significant $p$-values at $\alpha=0.05$. Z-scores are 5 presented in Table S6 for both lateral and ventral views.

6

\begin{tabular}{|c|c|c|c|c|c|c|c|c|}
\hline & Arg & Bel & Cos & Col & Tab & Par & Per & Tri \\
\hline Arg & & $\mathbf{0 . 0 0 1}$ & $\mathbf{0 . 0 0 1}$ & $\mathbf{0 . 0 0 1}$ & $\mathbf{0 . 0 0 1}$ & $\mathbf{0 . 0 0 1}$ & $\mathbf{0 . 0 0 1}$ & $\mathbf{0 . 0 0 1}$ \\
Bel & $\mathbf{0 . 0 0 1}$ & & 0.257 & $\mathbf{0 . 0 4 4}$ & $\mathbf{0 . 0 3 9}$ & 0.064 & $\mathbf{0 . 0 3 5}$ & 0.535 \\
Cos & $\mathbf{0 . 0 0 1}$ & 0.283 & & 0.569 & 0.079 & $\mathbf{0 . 0 0 6}$ & $\mathbf{0 . 0 3 3}$ & $\mathbf{0 . 0 3 7}$ \\
Col & $\mathbf{0 . 0 0 1}$ & 0.791 & 0.164 & & $\mathbf{0 . 0 1 3}$ & $\mathbf{0 . 0 0 2}$ & $\mathbf{0 . 0 1 3}$ & $\mathbf{0 . 0 1 1}$ \\
Tab & $\mathbf{0 . 0 0 1}$ & 0.157 & 0.269 & 0.084 & & 0.116 & 0.595 & $\mathbf{0 . 0 3 7}$ \\
Par & 0.096 & $\mathbf{0 . 0 0 1}$ & $\mathbf{0 . 0 0 1}$ & $\mathbf{0 . 0 0 1}$ & $\mathbf{0 . 0 0 1}$ & & $\mathbf{0 . 0 4 1}$ & 0.189 \\
Per & 0.088 & $\mathbf{0 . 0 0 6}$ & $\mathbf{0 . 0 0 2}$ & $\mathbf{0 . 0 0 1}$ & $\mathbf{0 . 0 1 9}$ & $\mathbf{0 . 0 0 4}$ & & 0.016 \\
Tri & 0.19 & $\mathbf{0 . 0 4 5}$ & 0.108 & $\mathbf{0 . 0 1 4}$ & 0.417 & $\mathbf{0 . 0 3 5}$ & 0.472 & \\
\hline
\end{tabular}

7 


\section{Table 4 (on next page)}

Table 4: Average centroid sizes for $A$. lituratus specimens by country with smallest values at the top and largest at the bottom. The order for the lateral view and ventral view is identical. 
1 Table 4: Average centroid sizes for A. lituratus specimens by country with smallest values at the 2 top and largest at the bottom. The order for the lateral view and ventral view is identical.

3

\begin{tabular}{|c|c|c|}
\hline & $\begin{array}{c}\text { Average Centroid } \\
\text { Size Lateral View }\end{array}$ & $\begin{array}{c}\text { Average Centroid } \\
\text { Size Ventral View }\end{array}$ \\
\hline Belize & 5.27 & 4.24 \\
Mexico, Colima & 5.33 & 4.33 \\
Costa Rica & 5.54 & 4.48 \\
Mexico, Tabasco & 5.55 & 4.53 \\
Argentina & 5.68 & 4.61 \\
Trinidad & 5.72 & 4.64 \\
Peru & 5.73 & 4.65 \\
Paraguay & 5.78 & 4.69 \\
\hline
\end{tabular}

4 